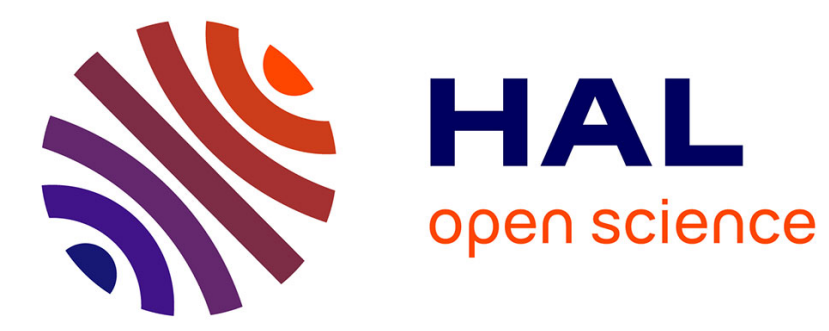

\title{
Microstructural statistics for fatigue crack initiation in polycrystalline nickel-base superalloys
}

\author{
Jean-Charles Stinville, William C. Lenthe, Mclean P. Echlin, Patrick G. \\ Callahan, Damien Texier, Tresa M. Pollock
}

\section{- To cite this version:}

Jean-Charles Stinville, William C. Lenthe, Mclean P. Echlin, Patrick G. Callahan, Damien Texier, et al.. Microstructural statistics for fatigue crack initiation in polycrystalline nickel-base superalloys. International Journal of Fracture, 2017, 208 (1-2), pp.221 - 240. 10.1007/s10704-017-0241-z . hal01662675

\section{HAL Id: hal-01662675 https://hal.science/hal-01662675}

Submitted on 13 Dec 2017

HAL is a multi-disciplinary open access archive for the deposit and dissemination of scientific research documents, whether they are published or not. The documents may come from teaching and research institutions in France or abroad, or from public or private research centers.
L'archive ouverte pluridisciplinaire HAL, est destinée au dépôt et à la diffusion de documents scientifiques de niveau recherche, publiés ou non, émanant des établissements d'enseignement et de recherche français ou étrangers, des laboratoires publics ou privés. 


\title{
Microstructural statistics for fatigue crack initiation in polycrystalline nickel-base superalloys
}

\author{
J. C. Stinville - W. C. Lenthe - M. P. Echlin • \\ P. G. Callahan - D. Texier • T. M. Pollock
}

\begin{abstract}
In advanced engineering alloys where inclusions and pores are minimized during processing, the initiation of cracks due to cyclic loading shifts to intrinsic microstructural features. Criteria for the identification of crack initiation sites, defined using elasticplastic loading parameters and twin boundary length, have been developed and applied to experimental datasets following cyclic loading. The criteria successfully quantify the incidence of experimentally observed cracks. Statistical microstructural volume elements are defined using a convergence approach for two nickelbase superalloys, IN100 and René 88DT. The material element that captures the fatigue crack-initiating features in René 88DT is smaller than IN100 due to a combination of smaller grain size and higher twin density.
\end{abstract}

Keywords Fatigue initiation volume element . Polycrystalline superalloys - Strain localization · Low cycle fatigue - Fatigue initiation - High resolution digital image correlation

J. C. Stinville ( $\varangle)$. W. C. Lenthe · M. P. Echlin .

P.G. Callahan · T. M. Pollock

University of California Santa Barbara, Santa Barbara, CA, USA

e-mail: stinville@engineering.ucsb.edu

D. Texier

Department of Mechanical Engineering, Ecole de Technologie Suprieure, Montréal, Canada

\section{Introduction}

Fatigue is one of the life limiting properties of polycrystalline nickel-base superalloys used widely in turbine disks for power generation and aerospace applications. While fatigue cracks may initiate at large pores or inclusions (Milligan et al. 2004; Li et al. 2004; Texier et al. 2016), such extrinsic defects are uncommon in alloys processed through advanced powder metallurgical routes. In the absence of such large imperfections, initiation often occurs at intrinsic defects, making fatigue life highly microstructure sensitive and lifetime prediction challenging (Cowles 1989; Pollock and Tin 2006). In high cycle fatigue, crack initiation and growth through the first few grains can account for $80 \%$ of fatigue life. This process results in substantial scatter in the fatigue life (Kumar et al. 2010; Stinville et al. 2015b). The identification of microstructural regions susceptible to crack nucleation and propagation is a critical step in both predicting fatigue life of current materials and designing new materials and processing approaches that result in improved fatigue life.

Crystallographic fatigue cracks in powder metallurgy disk alloys, in the high and low cycle fatigue regime, initiate due to strain localization near annealing twin boundaries in large grains that are favorably oriented for slip (Stinville et al. 2015b; Miao et al. 2009). Dislocation accumulation due to irreversible deformation during cycling results in large incompatibility stresses, ultimately nucleating a crack (Pineau 
and Antolovich 2009; Mughrabi 2006; Heinz and Neumann 1990). Fatigue cracks have been found to initiate in large grains at the tail of the grain size distribution in a variety of twin-containing materials during high cycle fatigue (Mineur et al. 2000; Stein et al. 2012; Thompson et al. 1956; Boettner et al. 1964). Initiation occurs in the large grains favorably oriented for slip (high resolved shear stress on slip systems) (Li et al. 2004; Davidson et al. 2007; Miao et al. 2009). Moreover, elastic anisotropy has been shown to induce significant stress heterogeneities from grain to grain (Wong and Dawson 2010; Stinville et al. 2015a), strongly influencing crack initiation, particularly at lower strain amplitudes (Heinz and Neumann 1990). Under low deformation amplitudes, Heinz and Neumann (1990) have shown that fcc materials exhibiting relatively strong elastic anisotropy experience elevated shear stresses at twin boundaries, which ultimately triggers local plasticity and crack initiation. SEM-based digital image correlation (DIC) investigations of interrupted fatigue tests, performed on a powder metallurgy disk alloy René 88DT, demonstrate that cracks initiate near long twin boundaries in favorably orientated grains with the activated slip system parallel to the twin boundary, i.e in a parallel slip configuration (Stinville et al. 2015b). The initiation sites occur near coherent twin boundaries in grains with a high Schmid factor or/and a high elastic modulus difference across the twin. Grains with Schmid factors that are just below the maximum value may also initiate cracks if they contain large twin boundaries with a high elastic modulus difference across the boundary (Stinville et al. 2015b). Based on these observations, a simple multi-parameter criterion for crack initiating twin boundaries has been developed for the nickel-base superalloy, René 88DT (Stinville et al. 2015b).

The recent ability to gather large 2D and 3D datasets that contain information on grain structure and orientation enables statistical analysis of the frequency of occurrence of life-limiting intrinsic and extrinsic defects. For most material properties, there exists a fundamental material element size (volume or area) that sufficiently contains the microstructures that control the property of interest. Examples of these volumetric reductions include representative volume elements (RVEs) (Gitman et al. 2007; Hill 1963), statistical volume elements (SVEs) (Ostoja-Starzewski 2006; Niezgoda et al. 2010), and statistically equivalent representative volume elements (SERVE) (Groeber et al. 2006; Swaminathan et al. 2006; Shan and
Gokhale 2002). SERVEs are often linked to continuum modeling assumptions and convergence of a given property, such as elastic modulus. Existing approaches have defined specialized RVEs that are augmented sets of sampled volume elements which are statistically selected to be representative, in aggregate. Statistical representative volume element sampling has been proposed and applied (Niezgoda et al. 2010; Qidwai et al. 2012; Groeber et al. 2008; McDowell et al. 2011) to materials such as titanium and fiber composites. However, a framework that rigorously accounts for the role of multiple microstructural features that are influential under plastic loading conditions has not yet been fully developed.

In this work, we use the concept of microstructural volume elements (MVE) (Echlin et al. 2014; Groeber et al. 2006) and microstructural-based statistically equivalent volume elements (M-SERVE) (Swaminathan et al. 2006; Shan and Gokhale 2002) as well as property volume elements (PVE) (Echlin and Pollock 2013; Echlin et al. 2011) and property-based statistically equivalent volume elements (P-SERVE) (Swaminathan et al. 2006; Shan and Gokhale 2002) to describe converged volumes for relevant microstructural features that are associated with strain localization and fatigue crack initiation in two nickel-base alloys. This volume element sampling methodology, combined with analytical property models, can be used to determine the material property value within a set of confidence bounds. In this study we examine the influence of twin boundary density on the MVE and PVEs for fatigue, in two different alloys. Specifically, crack initiation criteria (Stinville et al. 2015b) were applied to the experimentally observed crack initiation sites in two powder metallurgy disk alloys: IN100 and René 88DT. Subsequently, property volume elements (PVE) for fatigue crack initiation sites were determined for each of these alloys, and the implications for fatigue property variability are discussed.

\section{Experimental materials}

\subsection{Material}

Two polycrystalline nickel-base superalloys used for turbine disk applications were investigated in this research: René 88DT and IN100. These alloys both have have grain sizes that are between $10-50 \mu \mathrm{m}$ 
and contain multiple size populations of strengthening phases (indicated as $\gamma^{\prime}$ ), which grow from solution and in subsequent aging steps (Reed 2006). The unique microstructural and chemical attributes of each alloy are described presently.

The polycrystalline powder metallurgy processed nickel-base superalloy, René 88DT, has a nominal composition of $13 \mathrm{Co}, 16 \mathrm{Cr}, 4 \mathrm{Mo}, 4 \mathrm{~W}, 2.1 \mathrm{Al}, 3.7 \mathrm{Ti}$, $0.7 \mathrm{Nb}, 0.03 \mathrm{C}, 0.015 \mathrm{~B}$ (wt\%) (Krueger et al. 1992). The microstructure of the alloy consists of a $\gamma$ matrix and two populations of $\gamma^{\prime}$ precipitates: larger secondary and nm-scale tertiary $\gamma^{\prime}$ within the $\gamma$ grains (Krueger et al. 1992). The size of the secondary $\gamma^{\prime}$ phase is about $100-200 \mathrm{~nm}$, while tertiary $\gamma^{\prime}$ precipitates are several nanometers in diameter. Crystallographic features were previously studied using electron backscatter diffraction (EBSD) measurements (Miao et al. 2008) showing that the material possesses very weak crystallographic texture, a large population of $\Sigma 3$ boundaries ( $46 \%$ by 2D measurements and $70 \%$ by 3D measurements of the total boundary length fraction, Lenthe et al. 2016), an average grain size of $26 \mu \mathrm{m}$, and a low fraction of large grains on the order of two to five times of the average grain size.

The IN100 material was also powder metallurgy processed, having a composition of $12.4 \mathrm{Cr}, 18.5 \mathrm{Co}$, 4.7Ti, 5.5 Al, 3.2Mo, 0.8 $\mathrm{V}$ and $0.07 \mathrm{C} \mathrm{(wt} \%$ ). The average grain size of the IN100 material is $43 \mu \mathrm{m}$. The material contains primary, secondary, and tertiary $\gamma^{\prime}$ precipitates that form during cooling and aging steps (Milligan et al. 2004; Li et al. 2004). Also, the IN100 material has a twin boundary length fraction of $22 \%$ (2D measurement) that is about half as large as that of Rene 88DT, and also contains little crystallographic texture.

\subsection{Mechanical testing and sample characterization}

\subsubsection{High resolution strain localization measurements}

Mechanical testing was performed in-situ in a FEI Versa FEG system (FIB-SEM) to determine the macroscopic deformation response and the local strain states on the sample surface. In-situ mechanical tests were performed with strain rates of $10^{-3} / \mathrm{s}$ to $10^{-4} / \mathrm{s}$ on seven polished dogbone type samples with a $1 \mathrm{~mm} \times$ $3 \mathrm{~mm}$ gauge section. High resolution DIC experiments utilized a mechanical load cell that was inserted into the SEM. Macroscopic strain was tracked by measuring displacements between fiducial marks on the sample surface and also with an extensometer type strain gauge, which was monitored during loading. Sub-grain scale high resolution DIC measurements were made under load at macroscopic strains of approximately $0.3 \%$ (nominal elastic regime) and approximately $1 \%$ (after macroscopic yielding).

High resolution DIC (Jiang et al. 2016, 2017; Kammers and Daly 2013; Di Gioacchino and Quinta da Fonseca 2013; Stinville et al. 2015c) analyses were performed on the sets of SEM images captured at different strain levels, while under load, in order to determine the in-plane elastic-plastic strain field at the sample surface using methodologies developed and described in detail elsewhere (Stinville et al. 2015a). Another set of SEM images was captured after unloading from an initial macroscopic deformation of approximately $0.3 \%$ in order to measure the residual strains. High magnification images were taken at a horizontal field width of $85 \mu \mathrm{m}$ in order to reduce drift and spatial distortions (Stinville et al. 2015a). SEM images of size $4096 \times$ 3775 pixels were divided into custom sized subsets of $21 \times 21$ pixels, which were regularly spaced by a step size of 5 pixels in both the horizontal and vertical directions. The in-plane displacement fields at the microscopic scale were obtained using the commercial software (VIC-2D 2009). DIC measurements were constructed by comparing images from each deformation step to images of the undeformed specimen. The axial loading direction will be referred to as the x-direction and horizontally oriented in all strain maps. The grain orientations from the DIC measurement areas were collected using electron backscatter diffraction (EBSD) measurements using a EDAX OIM-Hikari XM4 electron back-scatter diffraction detector, with an accelerating voltage of $20 \mathrm{keV}$, a $4 \times 4$ binning mode and a beam current of $0.2 \mathrm{nA}$. The average grain orientation, highest Schmid factor (calculated assuming uniaxial loading), and elastic modulus maps were obtained from the average crystallographic orientation of each grain along the loading direction and the compliance matrix of a nickel superalloy (Stinville et al. 2016).

\subsubsection{Fatigue experiments}

Cyclic testing was performed in air at room temperature in the low cycle fatigue regime. Low cycle fatigue 
tests were performed in a symmetric, uniaxial, pushpull mode on an electromechanical machine. Tests were carried out in stress control mode for René 88DT and IN100 at maximum stresses of 758 or $930 \mathrm{MPa}$, with R-ratios of -1 and 0.1 respectively at a frequency of $1 \mathrm{~Hz}$. Four cylindrical René 88DT specimens with a gauge diameter of $5 \mathrm{~mm}$ and gauge length of $16 \mathrm{~mm}$ were used in this study to obtain the number of cycles to fracture. Four flat dogbone type samples with a 2 $\times 3 \mathrm{~mm}$ gauge section were used to test the IN100 superalloy. Fatigue tests were interrupted at 45 and $80 \%$ of lifetime to capture information on crack initiation sites. Initiation sites were correlated to the grain structure using EBSD measurements, according to the procedure outlined in more detail elsewhere (Stinville et al. 2016). EBSD measurements were collected from two selected René 88DT fatigue specimens with two adjacent machined flat areas in the gauge section that were $2.5 \mathrm{~mm}$ in width and $8 \mathrm{~mm}$ in length. The two flats were positioned on opposite sides of the specimen gauge section. Samples were electropolished in a solution of $10 \%$ perchloric acid and $90 \%$ ethylene glycol at $30 \mathrm{~V}$ for $30 \mathrm{~s}$ to remove residual surface stresses.

\subsection{Computational analysis}

Analysis of the EBSD data was performed using routines developed in $\mathrm{C}++$. Grains were segmented with a $5^{\circ}$ tolerance with grain orientations averaged in cubochoric space (Rosca et al. 2014). The directional elastic modulus parallel to the loading direction and the maximum Schmid factor were computed for each grain using the average orientation of the grain. Grain boundaries were meshed with line segments that separate pixels that belong to different grains and the length of each grain boundary was measured. The disorientation across each grain boundary was computed using the average orientation of the two bounding grains and boundaries with a disorientation axis within $5^{\circ}$ of $\{111\}$ and disorientation angle within $5^{\circ}$ of $60^{\circ}$ considered to be twin boundaries. For each twin boundary, the coherent direction was calculated and boundaries with the maximum Schmid factor slip system in the coherent $\{111\}$ plane identified. Twin boundaries with a critical combination of Schmid factor, elastic modulus mismatch, length, and slip configuration were identified (Stinville et al. 2016). Thousands of twin related domains were identified by merging all grains con- nected with a twin boundary into a single grain cluster (parent grain and associated twins), and the number of twin boundaries satisfying the initiation criteria counted for each cluster.

\section{Experimental results}

\subsection{Strain localization during monotonic tensile testing}

The SEM DIC technique described in Sect. 2.2.1 has enabled the measurement of strain heterogeneities introduced by elastic-plastic deformation at the $\mu \mathrm{m}$ scale in René 88DT and IN100 superalloys. Sub-grain DIC measurements have been performed at several adjacent regions of interest after tensile loading to approximately $0.3 \%$ and approximately $1 \%$ macroscopic strain (Figs. 1, 2). The DIC strain measurements were related to the grain microstructure as determined by EBSD mapping. The extent of localization in René 88DT and IN100 is shown $\left(\epsilon_{x x}\right)$ with respect to the microstructure for the regions of interest that were stitched together in Figs. 1b, d and 2b, d respectively. The $\epsilon_{x x}$ strain field was also measured after unloading from initial straining at approximately $0.3 \%$ for René 88DT and IN100 and shown in Figs. 1c and 2c respectively. The associated EBSD map, elastic modulus map and Schmid factor maps for the $\{111\}\langle 110\rangle$ slip systems according to the macroscopic loading direction are displayed in Figs. 1a, e, f and 2a, e, f respectively.

Bands of concentrated strain, that correspond to slip band formation, directly correlate with the grain structure of the René 88DT and IN100 superalloys. The bands of concentrated strain that occur at $0.31 \%$ macroscopic strain in IN100 are localized near twin boundaries, as indicated with arrows in Fig. 2a, c. Bands of concentrated strain occur near and parallel to twin boundaries in twin and parent grain pairs that exhibit either very high Schmid factor or relatively high Schmid factor with a large elastic modulus difference across their twin boundary. At $0.28 \%$ macroscopic strain in René 88DT, the highest strains are also observed near twin boundaries. For instance, at the arrow in Fig. 1e, a twin and parent grain pair is shown that has a high elastic modulus difference across the twin boundary. Interestingly, strain localizations observed at $0.28 \%$ macroscopic strain in René 
Fig. 1 Strain field $\epsilon_{x x}$ from high resolution DIC after $0.28 \%(\mathbf{b})$ and $0.98 \%(\mathbf{d})$ macroscopic strain in tension for René 88DT. The associated EBSD map (before loading), elastic modulus and Schmid factor maps referenced to the uniaxial macroscopic direction are reported in (a), (e) and (f). The horizontal $\mathrm{x}$ direction is the loading direction. c Strain field $\epsilon_{x x}$ from high resolution DIC after unloading from an initial deformation of $0.28 \%$ (b)

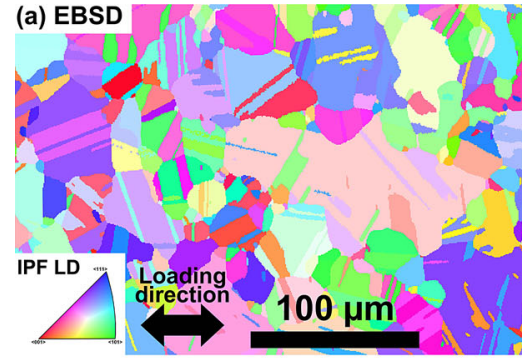

(b) $0.28 \%$ macroscopic strain
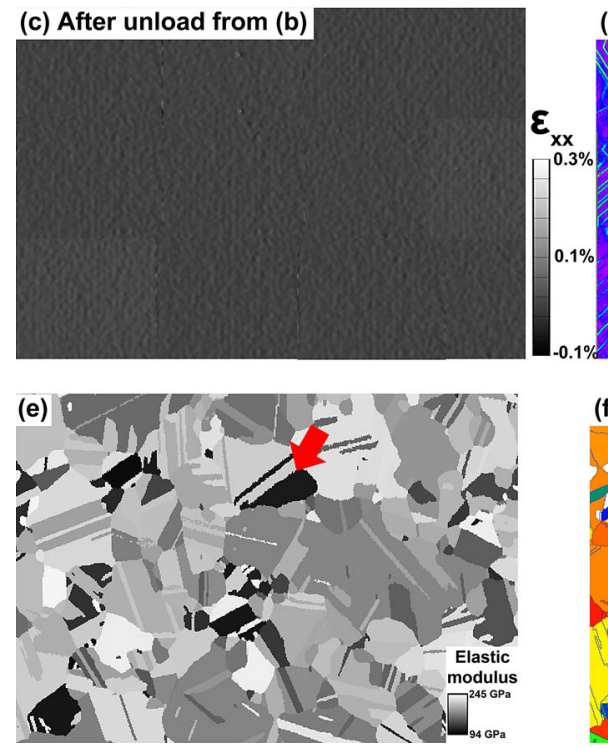

(d) $0.98 \%$ macroscopic strain
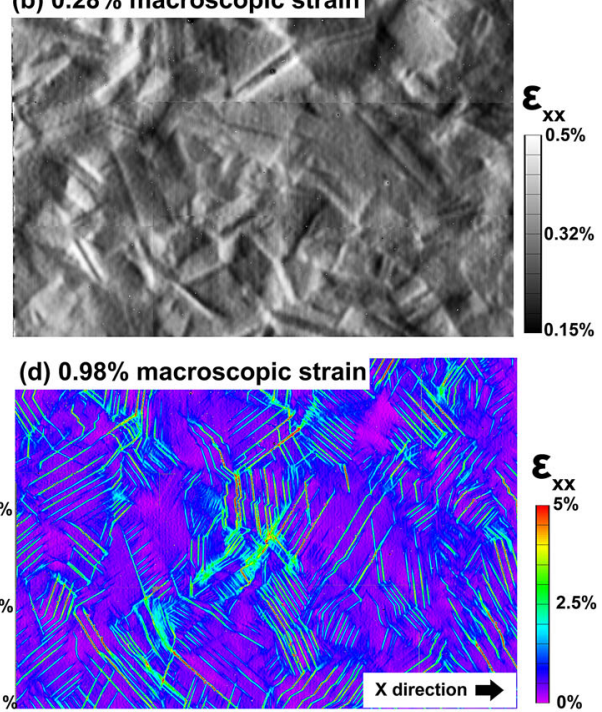

$\mathcal{E}_{\mathbf{x x}}$

$2 \%$

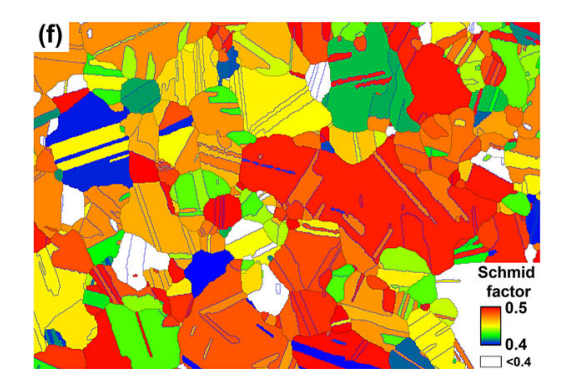

88DT were purely elastic with no residual bands of concentrated strain detected after unloading.

The highest degree of localization observed for both René 88DT and IN100 superalloys, at approximately $1 \%$ macroscopic deformation (above yielding), was always observed near twin boundaries. For each band of concentrated strain, the average value of the shear strain along the band was calculated using the methodology described in reference (Stinville et al. 2015a). The bands of concentrated strain with the two highest shear strain values are displayed in Figs. 3 and 4 for IN100 and René 88DT respectively. The highest strain localizations are systematically observed near twin boundaries in a parallel slip configuration (Stinville et al. 2015a), where the activated slip plane with the highest Schmid factor is parallel to the twin plane. In addition, large elastic modulus differences across the twin boundaries are observed for these twin and parent grain pairs.

The bands of concentrated strain corresponding to the five highest shear strains are displayed in Fig. 5a.
Each band was was located parallel and near a twin boundary in a twin and parent grain pair with a parallel slip configuration (Stinville et al. 2015a). In both IN100 and René 88DT superalloys, the configuration that favors either a high Schmid factor or a large elastic modulus difference between the twin and parent pair has the highest shear strain along the activated slip band. With regard to crystallographic considerations, when slip transmission does not occur at twin boundaries, i.e. the activated slip systems are parallel to the twin boundaries, then the Schmid factors of the activated systems in the twins and the parent grains have the same value (Stinville et al. 2015a). Therefore, a single Schmid factor can be associated with a twin and parent grain pair. The highest Schmid factors on the activated plane for the twin and parent grain pairs that have the highest strain localization are displayed in Fig. 5b, according to the elastic modulus difference across their twin boundary. The black dashed line indicates the theoretical limit of the elastic modulus difference across a twin boundary for a given maximum Schmid factor on 
Fig. 2 Strain field $\epsilon_{x x}$ from high resolution DIC after $0.31 \%(\mathbf{b})$ and $1 \%(\mathbf{d})$ macroscopic strain in tension for IN100.

Associated EBSD map (before loading), elastic modulus and Schmid factor map references to the uniaxial macroscopic direction are reported in (a), (e) and (f). The horizontal $\mathrm{x}$ direction is the loading direction. c Strain field $\epsilon_{x x}$ from high resolution DIC after unloading from an initial deformation of $0.31 \%$ (b)
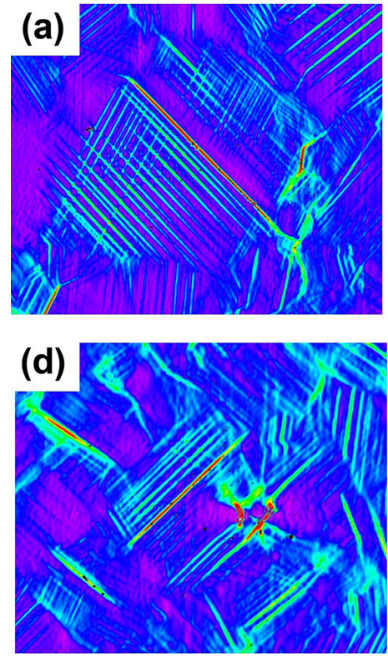
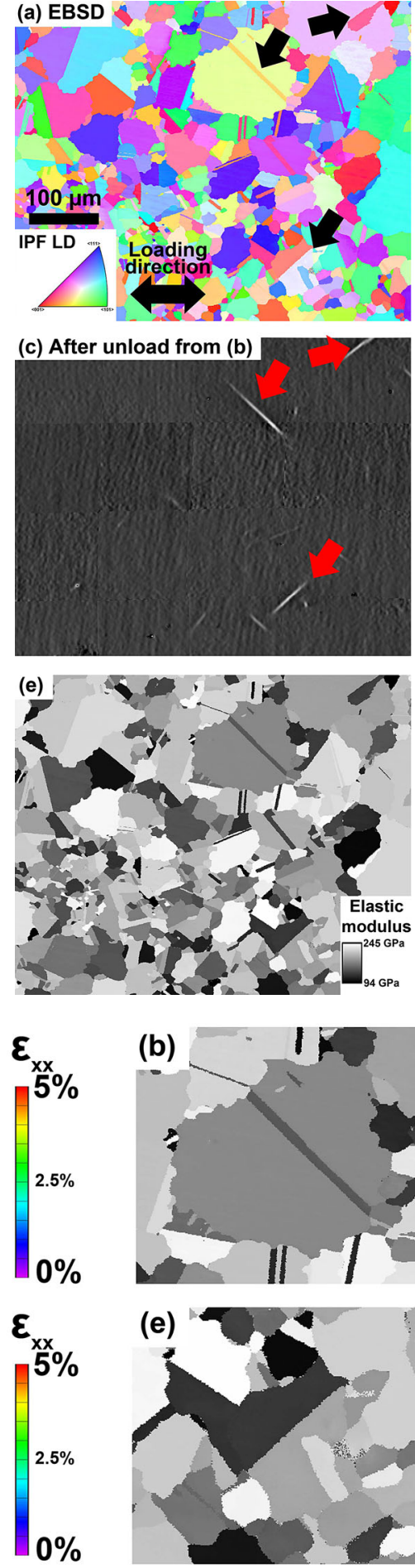

(c) After unload from (b)
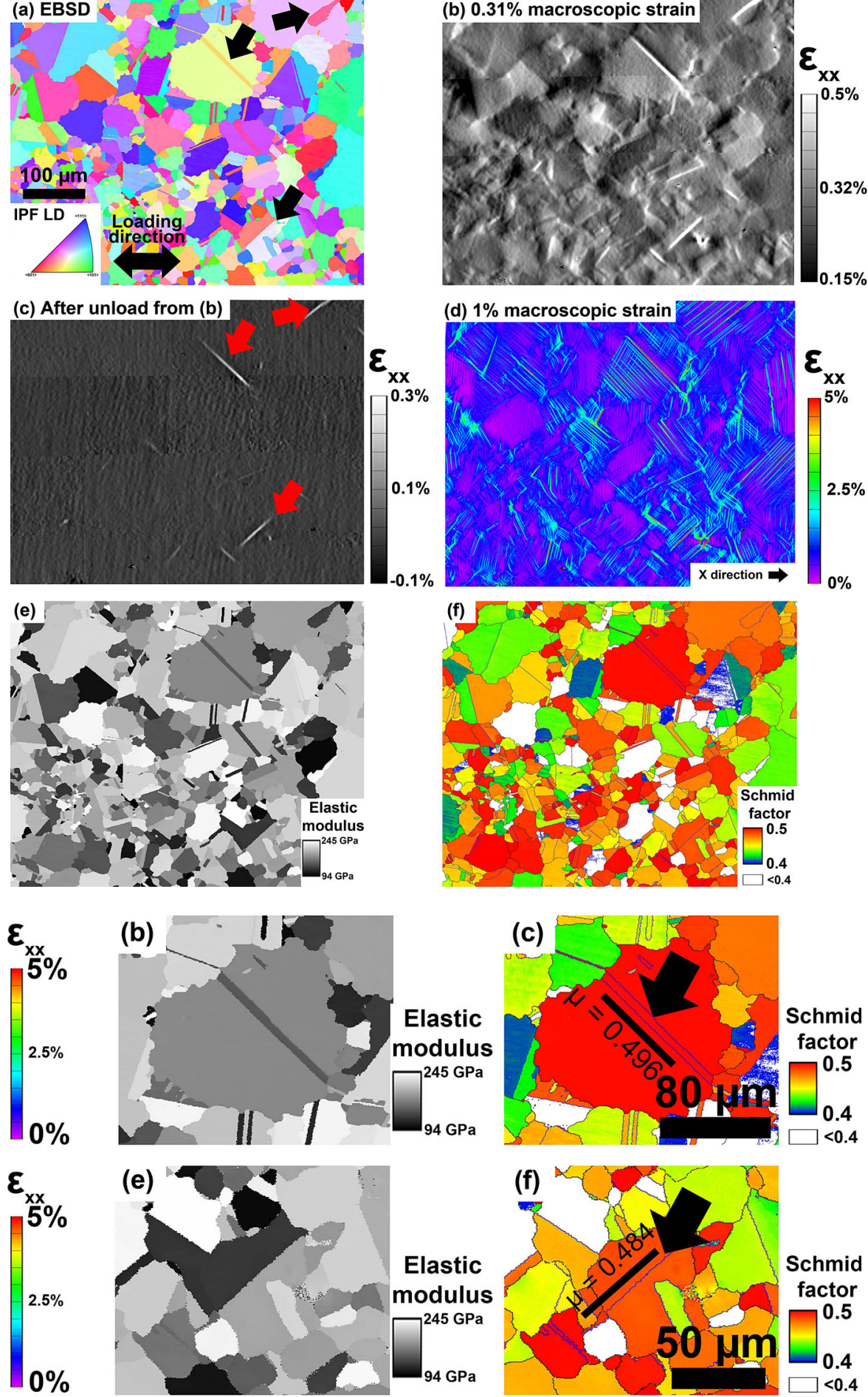

Fig. 3 The highest strain localization bands observed on the investigated region for IN100. a, d Strain field $\epsilon_{x x}$ from high resolution DIC after 1\% macroscopic strain in tension for IN100. The associated elastic modulus and Schmid factor map refer- enced to the uniaxial macroscopic direction are reported in $(\mathbf{b}$, e) and (c, f) respectively. The surface traces of the $\{111\}\langle 110\rangle$ slip systems with the highest Schmid factor for the grains with the highest strain localization bands are displayed in $(\mathbf{c}, \mathbf{f})$ 

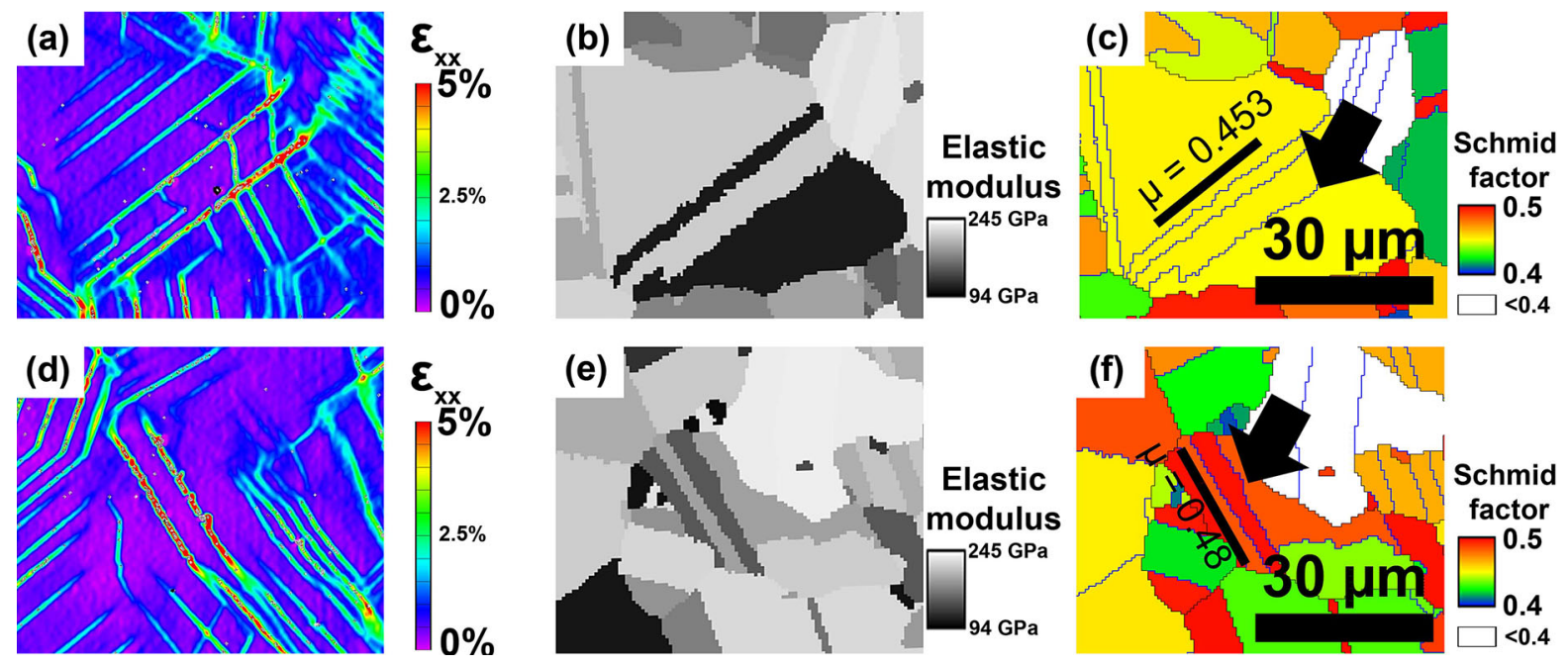

Fig. 4 The highest strain localization bands observed on the investigated region for René 88DT. a, d Strain field $\epsilon_{x x}$ from high resolution DIC after $0.98 \%$ macroscopic strain in tension for René 88DT. The associated elastic modulus and Schmid factor map referenced to the uniaxial macroscopic loading direction are reported in $(\mathbf{b}, \mathbf{e})$ and $(\mathbf{c}, \mathbf{f})$ respectively. The surface traces of the $\{111\}\langle 110\rangle$ slip systems with the highest Schmid factor for the grains with the highest strain localization bands are displayed in $(\mathbf{c}, \mathbf{f})$ (a)

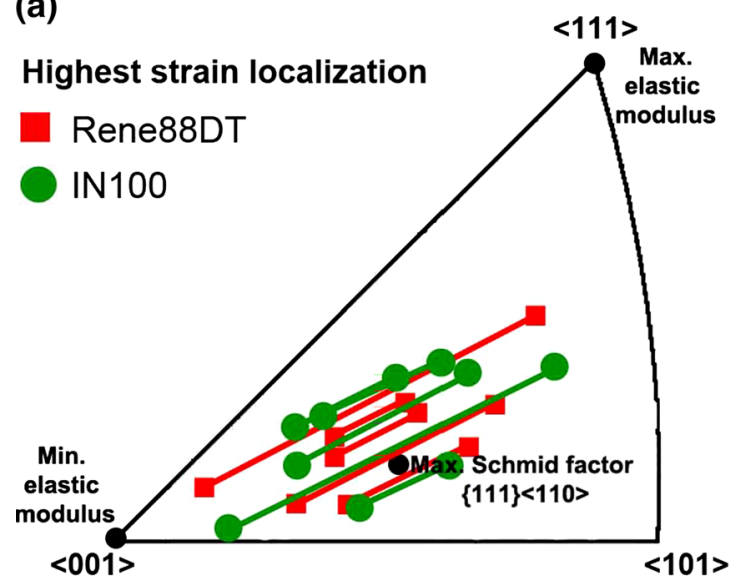

Fig. 5 The orientations of the twin and parent grain pairs exhibiting the highest shear strain localization at approximately $1 \%$ macroscopic strain in tension as measured using high resolution DIC on René 88DT and IN100. a An IPF map with superimposed parent-twin grain pair orientations connected via lines. Red and green lines connect the orientation of the twin and

the plane parallel to the twin boundary plane. The highest strain localizations occur in grains that maximize the elastic modulus difference for a given maximum Schmid factor.

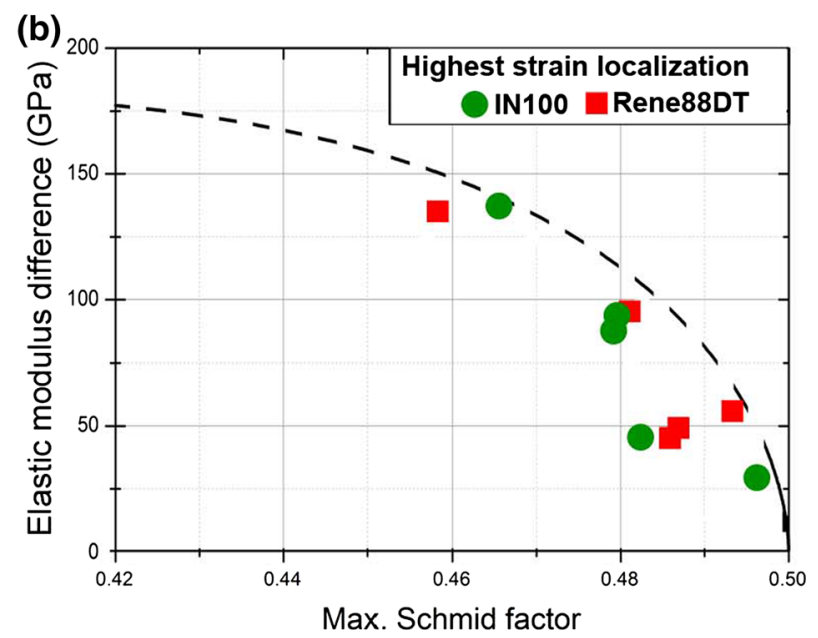

his associated parent grain. b Elastic modulus difference according to the maximum Schmid factor of the twin and parent grain pairs which present the highest shear strain localization. The dotted line in (b) indicates the theoretical limit of elastic modulus difference according the Schmid factor for a twin and parent grain pair in parallel slip configuration

\subsection{Grain configurations favoring crack initiation}

Interrupted fatigue tests were conducted to assess the microstructure associated with the initiation sites as described in Sect. 2.2.2. Multiple cracks at the surface of the fatigue specimens within individual grains 

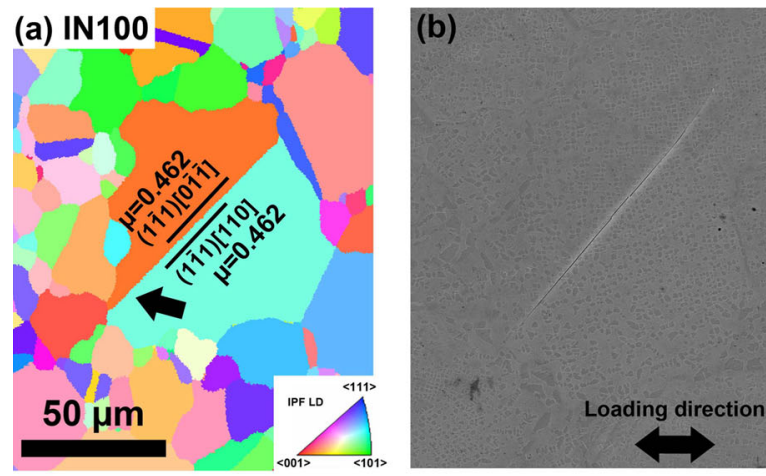

(e) Rene 88DT
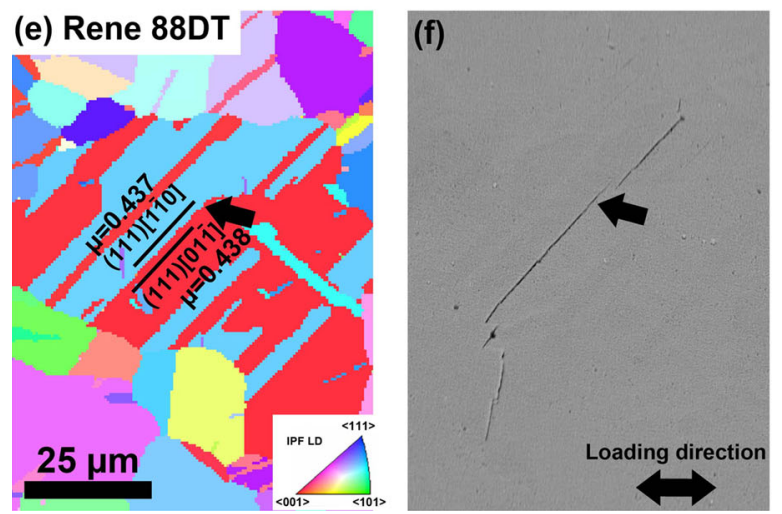

Fig. 6 Grains with cracks after fatigue tests interrupted at $45 \%$ of the lifetime on the René 88DT and IN100: a, e inverse pole figure map; b, f associated SEM images; $\mathbf{c}, \mathbf{g}$ associated highest

were observed during cycling. In the IN100 superalloy, several cracks were observed to initiate at defects such as non-metallic inclusions (Milligan et al. 2004; Li et al. 2004; Texier et al. 2016) and were not considered in the present study. Instead, the cracks investigated were located at crystallographic configurations such as those displayed in Fig. 6b, f for the IN100 and René 88DT alloys. The associated EBSD, Schmid factor and elastic modulus maps are also given in Fig. 6a-e, c$\mathrm{g}, \mathrm{d}-\mathrm{h}$. All the cracks associated with crystallographic configurations were detected near to and parallel with a twin boundary, without exception. Furthermore, the twin and parent grain pairs that initiated cracks all have the parallel slip configuration (Stinville et al. 2016).

The elastic modulus difference versus maximum Schmid factor for twin and parent grain pairs that initiate cracks after $80 \%$ of the lifetime for a specimen tested in fatigue (see Ref. Stinville et al. 2016 for experimental details) is presented in Fig. 7a for René 88DT (red squares) and IN100 (green circles). Depending
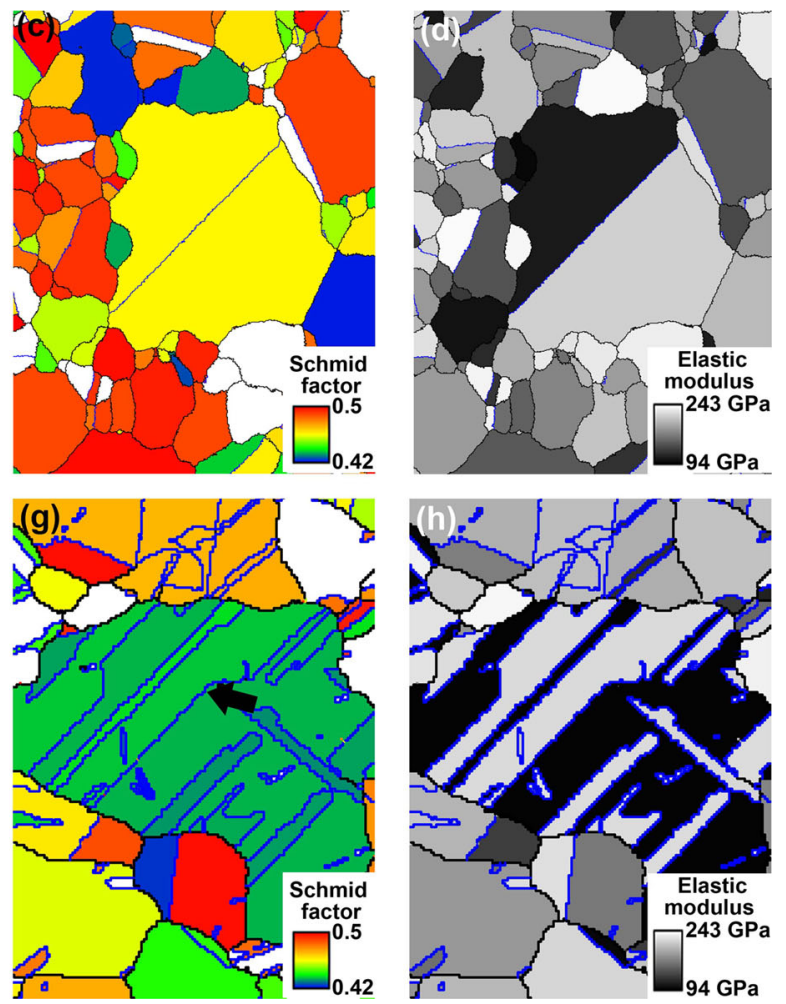

Schmid factor map; $\mathbf{d}, \mathbf{h}$ associated elastic modulus map. The active $\{111\}\langle 110\rangle$ slip system with the highest Schmid factor is indicated in $(\mathbf{a}, \mathbf{e})$

on the maximum Schmid factor of the twin and parent grain pair, there exists a threshold value of elastic modulus difference below which the twin and parent grain pairs do not initiate a crack (gray area in Fig. 7a). A polynomial function was used to bound the elastic modulus-Schmid factor domain. As observed for the strain localization under monotonic loading, grain pairs that initiate cracks maximize elastic modulus difference for a given maximum Schmid factor.

Figure $7 \mathrm{~b}$ presents the twin boundary length versus the maximum Schmid factor of the twin and parent grain pairs found to initiate a crack at $80 \%$ of the lifetime for the René 88DT (red squares) and IN100 (green circles). Depending on the maximum Schmid factor of the twin and parent grain pair, there exists a threshold value of the twin boundary length, below which the twin and parent grain pairs do not initiate cracks (gray area in Fig. 7b). Grains that belong to the domains defined by gray areas shown in Fig. 7a, b have not been observed to initiate cracks in the more than 20,000 investigated 


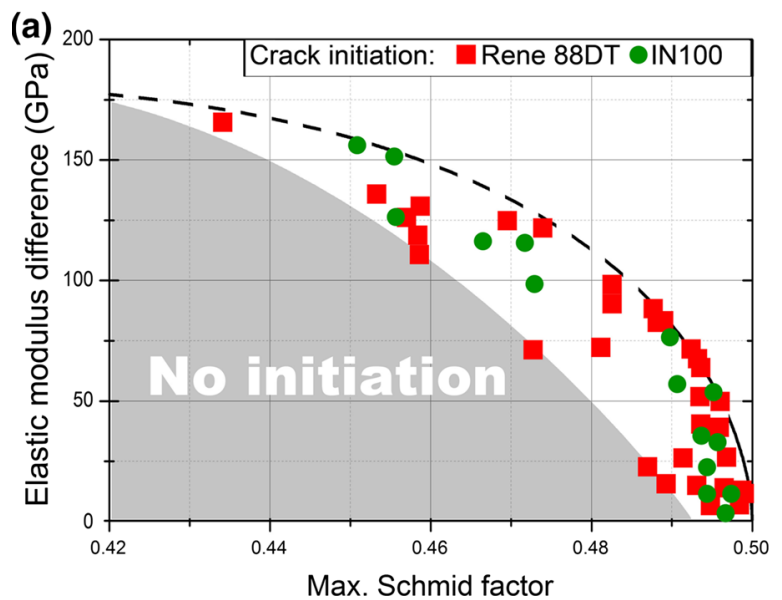

Fig. 7 a Elastic modulus difference according to the maximum Schmid factor of the twin and parent grain pairs which initiate cracks after $80 \%$ of the lifetime in René 88DT (red square) and IN100 (green circle). b Boundary length according to the maxi-

grains, which corresponds to several $\mathrm{mm}^{2}$ of examined surface area.A linear function is used to bound the domain twin boundary length-Schmid factor. It is observed in Fig. 7b that grains with twin boundaries with lengths greater than the average grain size have a greater possibility to initiate cracks than boundaries with lengths smaller than the average grain size. For more detail on this aspect of fatigue in René 88DT, the reader is referred to a previous publication (Stinville et al. 2016).

\subsection{Application of crack-initiation criteria to} millimeter-scale data: analysis of the character of twin distributions

From strain localization and crack initiation data it is possible to define a critical domain bounded by the maximum Schmid factor, using the elastic modulus difference and the twin boundary length to predict grains amenable to crack initiation. Such a domain was used to predict the crack initiation sites from large EBSD maps that have a statistically significant number of grains for both the René 88DT and IN100 materials.

Grain boundaries were segmented as described in Sect. 2.3 and twin boundaries identified as shown in Fig. 8b. Twin boundaries parallel to the highest Schmid factor slip system (in the parallel slip configuration) on both sides of the boundary are identified in Fig. 8c

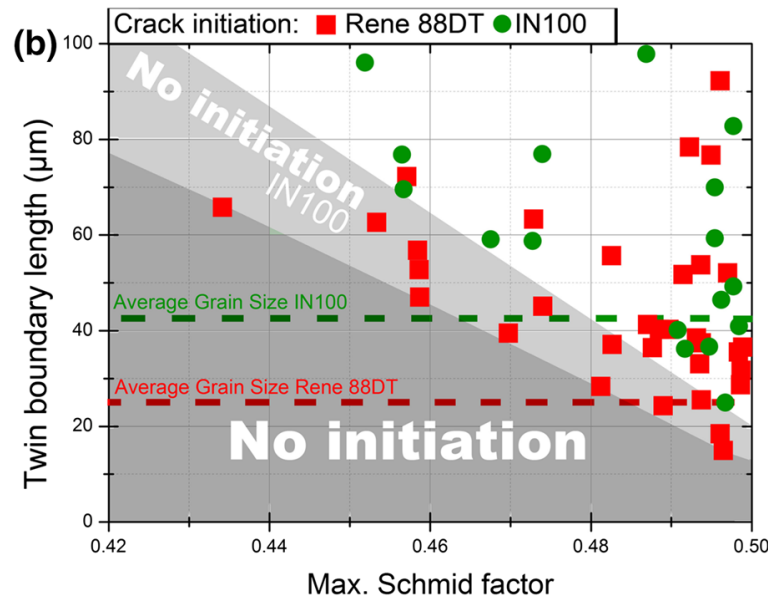

mum Schmid factor of the twin and parent grain pairs which initiate cracks after $80 \%$ of the lifetime in René 88DT (red square) and IN100 (green circle)

by assuming twin boundaries are coherent and have a prescribed uniaxial loading direction. Twin boundaries in fcc materials were previously demonstrated to be coherent by means of datasets collected using the TriBeam microscope (Echlin et al. 2015) for 3D microstructural twin analysis (Lenthe et al. 2016). The boundary length, maximum Schmid factor, and elastic modulus difference across the boundary were also computed as displayed in Fig. 8d-f. The Schmid factor is the maximum of the 24 Schmid factors calculated from the orientation of the grains on both sides of the boundary.

Millimeter square $\left(\sim 2 \mathrm{~mm}^{2}\right.$ for René $88 \mathrm{DT}$ and $\sim 8$ $\mathrm{mm}^{2}$ for IN100) scale EBSD scans were collected from the René 88DT and IN100 specimens. Twin boundaries and twin boundaries in the parallel slip configuration are identified and displayed for a portion of the investigated area in the René 88DT and IN100 material in Fig. 9a, $d$ and b, e. The length fraction of twin boundaries is given for both alloys in Table 1 . The IN100 superalloy has a twin length faction of $22.1 \%$, while the René 88DT superalloy has a length fraction of $46.2 \%$. The length fraction of twin boundaries in the parallel slip configuration in comparison to all boundaries is as low as 3\% and 7\% in IN100 and René 88DT superalloys, respectively. Twin boundaries and twin boundaries in a parallel slip configuration are plotted according to the elastic modulus difference across their twin, 


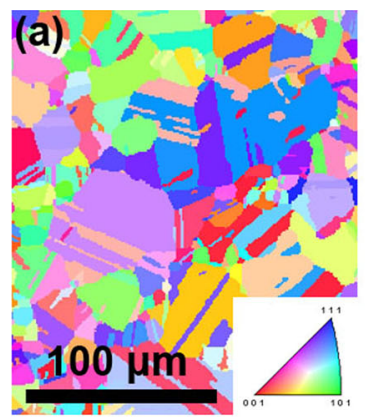

(d) Boundary length $J_{k}^{m}$

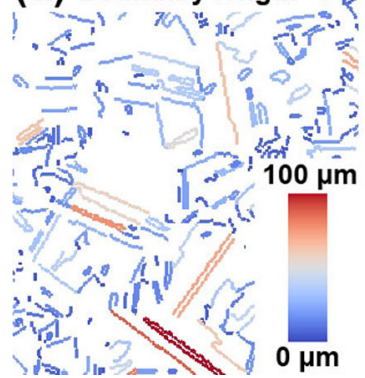

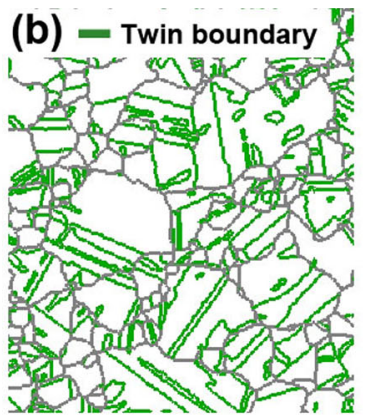

(e) Max. Schmid factor

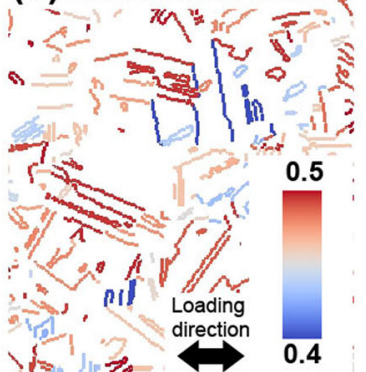

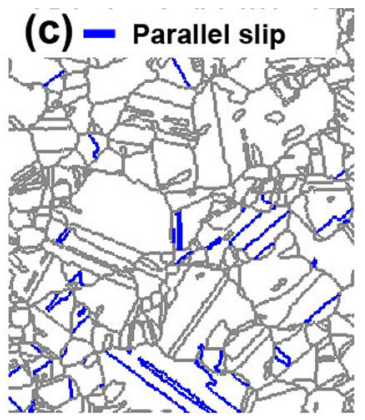

(f) Modulus difference

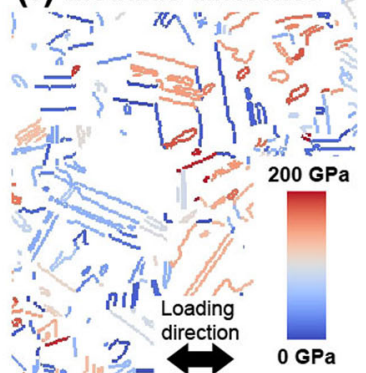

Fig. 8 A summary of the EBSD dataset surface mesh analysis is presented for René 88DT. a Initial EBSD dataset. b Grain and twin boundaries (green) are identified with a $2^{\circ}$ misorientation tolerance. $\mathbf{c}$ The coherent direction for each twin boundary is computed and boundaries with the highest Schmid factor slip system parallel to the coherent plane identified (blue). d The length for each boundary is computed by projection along the coherent plane trace. e The maximum Schmid factor for each grain on both sides of the boundary is computed and associated with the boundary. $\mathbf{f}$ The elastic modulus difference across the boundary is computed according to the macroscopic loading direction

removes 80.1 and $73.6 \%$ of all twin boundaries that are in a parallel slip configuration from the initiation candidates in each of the two materials. The boundary length and boundary fraction of twin and parent grain pairs in the parallel slip configuration that pass the Elastic modulus difference-maximum Schmid factor and boundary length—-maximum Schmid factor criteria are given in Table 1.

Boundaries that are candidates for initiation according to the initiation criteria (parallel slip configuration and threshold on elastic modulus difference, boundary length and maximum Schmid factor) represent $1.0 \%$ of the boundary length in IN100 and 2.9\% in René 88DT.

The initiation candidates extracted from EBSD data acquired from an IN100 specimen prior to fatigue testing are presented in Fig. 11a. Surface investigations after cycling (interrupted before fracture) using SEM were also conducted in the same region where the EBSD data was acquired. All cracks that were observed on the surface of the EBSD map are displayed in Fig. 11b. A total of 5 cracks were experimentally observed to initiate at the surface within the 
(a) IN100: - Twin boundary

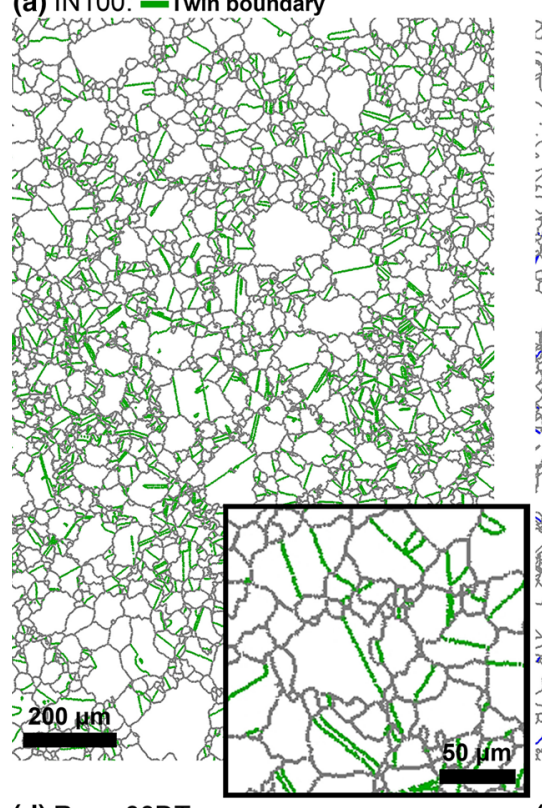

(d) Rene 88DT: - Twin boundary

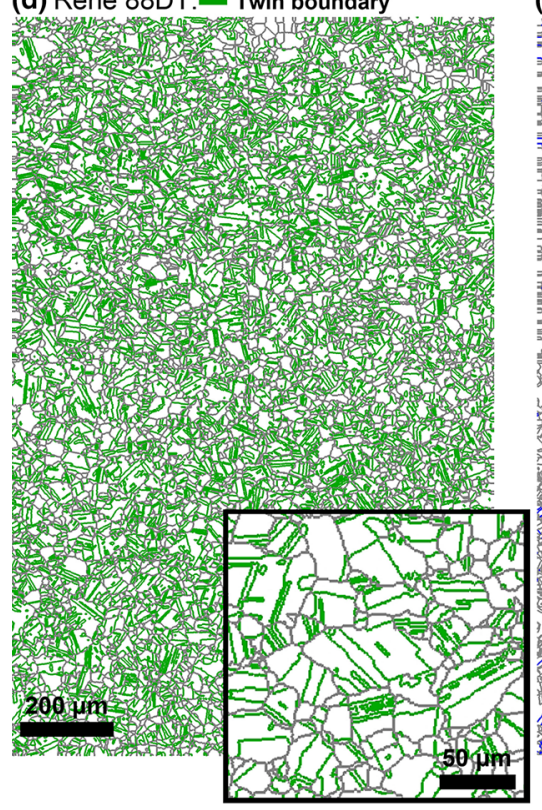

Fig. 9 A summary of the EBSD dataset surface mesh analysis is presented for IN100 (a-c) and René 88DT $(\mathbf{d}-\mathbf{f})$. a, d Grain and twin boundaries (green) are identified with a $2^{\circ}$ tolerance on misorientation. b, e The coherent direction for each twin boundary is computed and boundaries with the highest Schmid factor slip

region investigated by EBSD. Each crack occurred near a twin boundary that was correctly predicted as an initiation candidate using the initiation criteria, as defined in Fig. 10a. However, several sites predicted by the
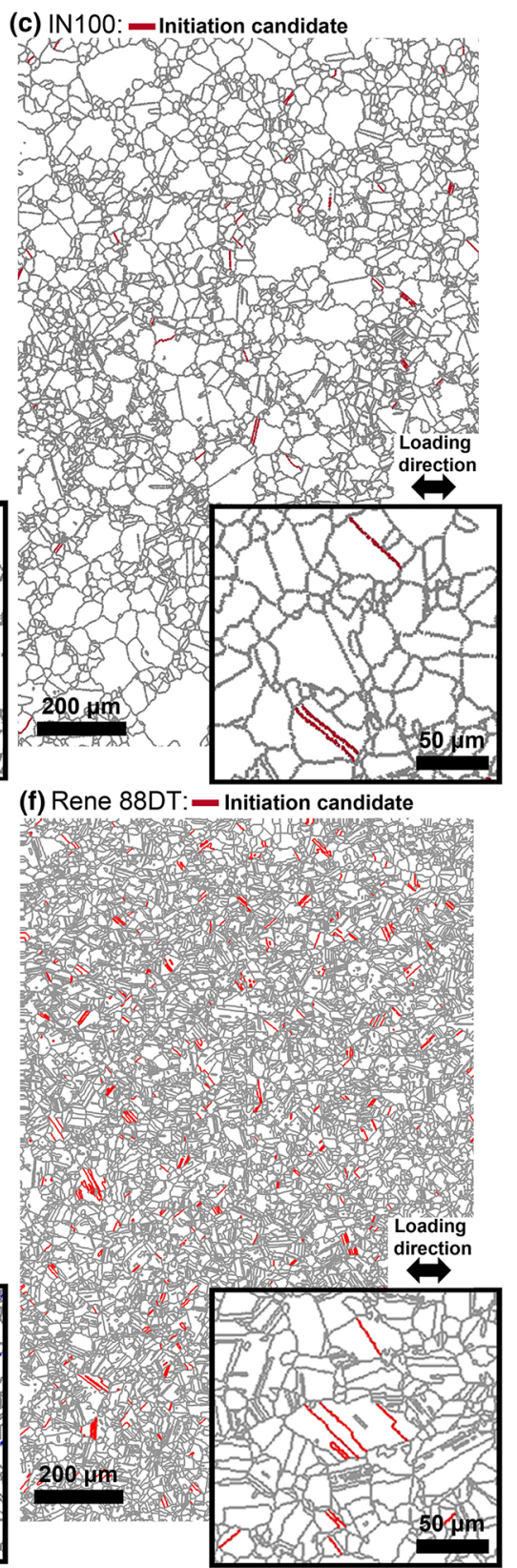

(e) Rene 88DT:-Twin boundary in parallel slip

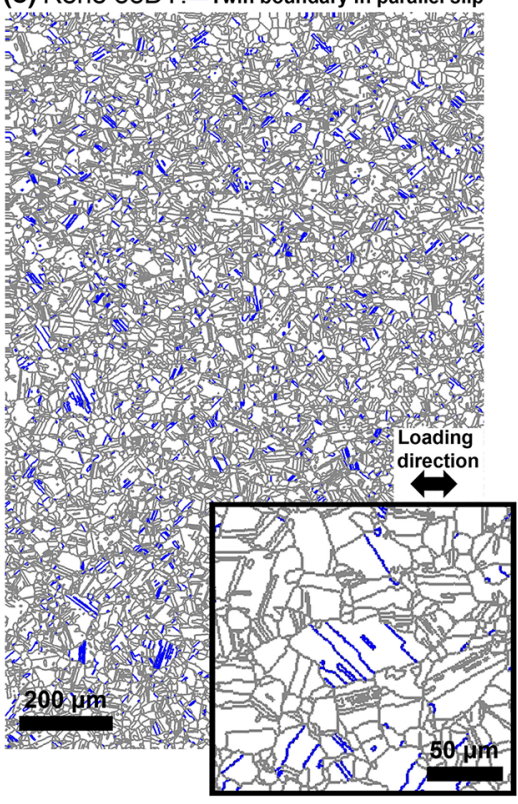

system parallel to the coherent plane identified (blue). c, d The criteria for fatigue crack initiation is applied using a threshold on twin boundary length, elastic modulus difference and maximum Schmid factor on twin and parent grain that have the slip system with the highest Schmid factor parallel to the twin boundary

initiation criteria, such as those labeled (A, B, C, E) and $(\mathrm{F})$ in Fig. 11a, displayed strain localization, but not to the point where cracks initiated during cyclic loading. 
Table 1 Boundary length and boundary fractions for IN100 and René 88DT superalloys

\begin{tabular}{lll}
\hline & IN100 & René 88DT \\
\hline Boundary length fraction (\%) & & 46.2 \\
Twin boundary & 22.1 & 7 \\
Twin boundary in parallel slip configuration Stinville et al. (2016) & 3 & 2.9 \\
Initiation criteria & 1.0 & $68.2(67.5)$ \\
Parallel slip configuration twin boundary: length fraction and (boundary fraction) (\%) & $64.3(65.6)$ & $48.5(26.4)$ \\
Maximum Schmid factor-elastic modulus difference criteria (see Fig. 5a) & $41.4(19.9)$ & \\
Maximum Schmid factor-twin length criteria (see Fig. 5b) &
\end{tabular}

(a) IN100

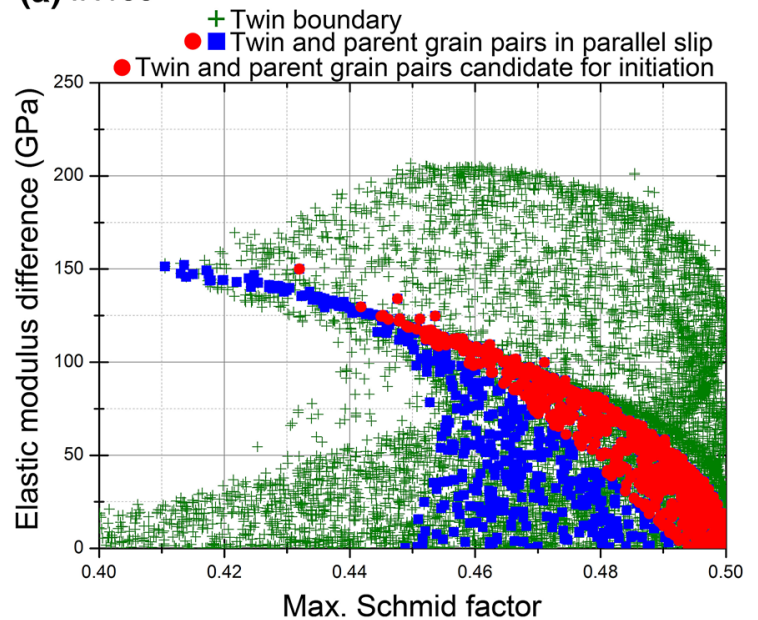

(c) Rene 88DT

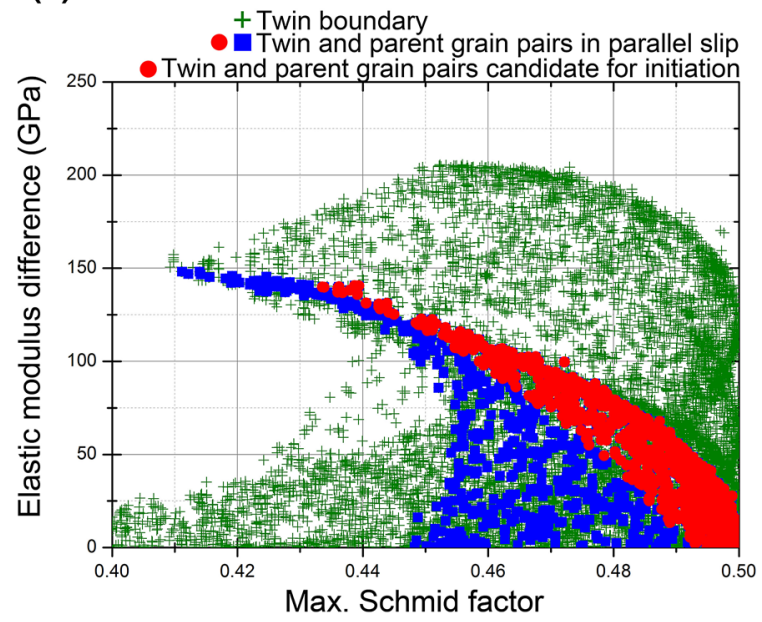

Fig. 10 Twin boundary distribution according to the associated highest Schmid factor, elastic modulus difference across their boundary, and boundary length for IN100 (a, b) and René 88DT (c, d). Twin boundaries which have a parallel slip configuration are display in blue. a, $\mathbf{c}$ The criteria for fatigue crack initiation is applied using a threshold on elastic modulus difference and

\section{(b) IN100}

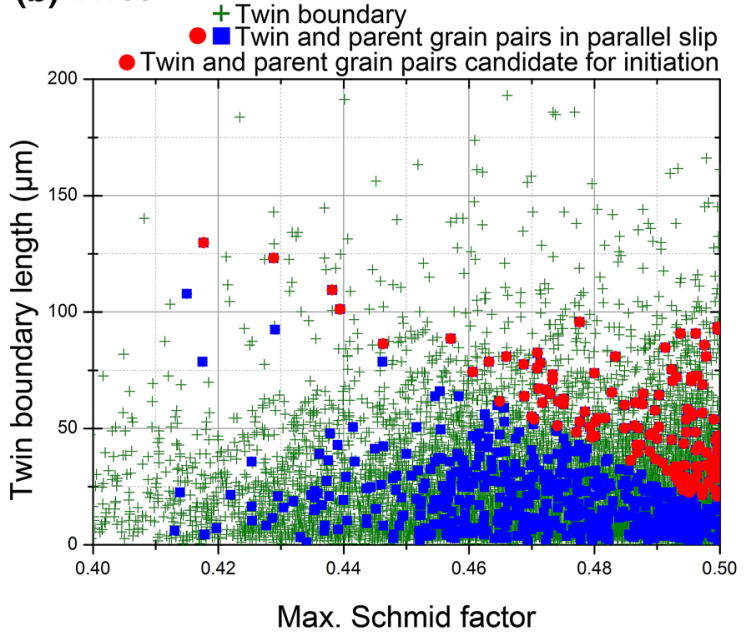

(d) Rene 88DT

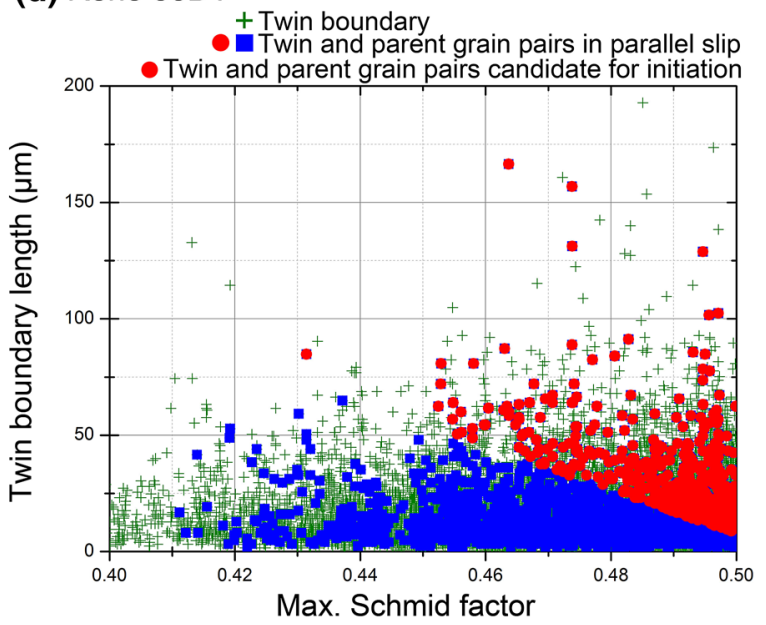

maximum Schmid factor on twin and parent grains that have slip system with the highest Schmid factor parallel to the twin boundary. $\mathbf{b}, \mathbf{d}$ The criteria for fatigue crack initiation is applied using a threshold on boundary length and maximum Schmid factor on twin and parent grain that have the slip system with the highest Schmid factor parallel to the twin boundary 
(a) Initiation candidate

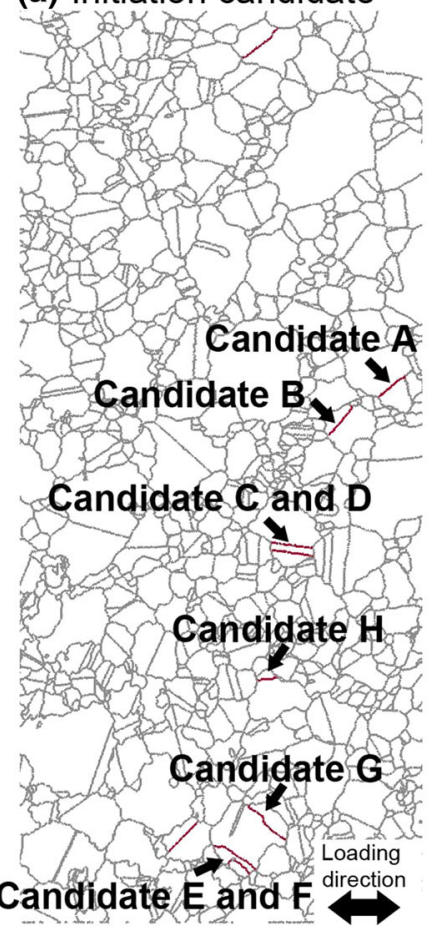

(b) Crack Initiation site

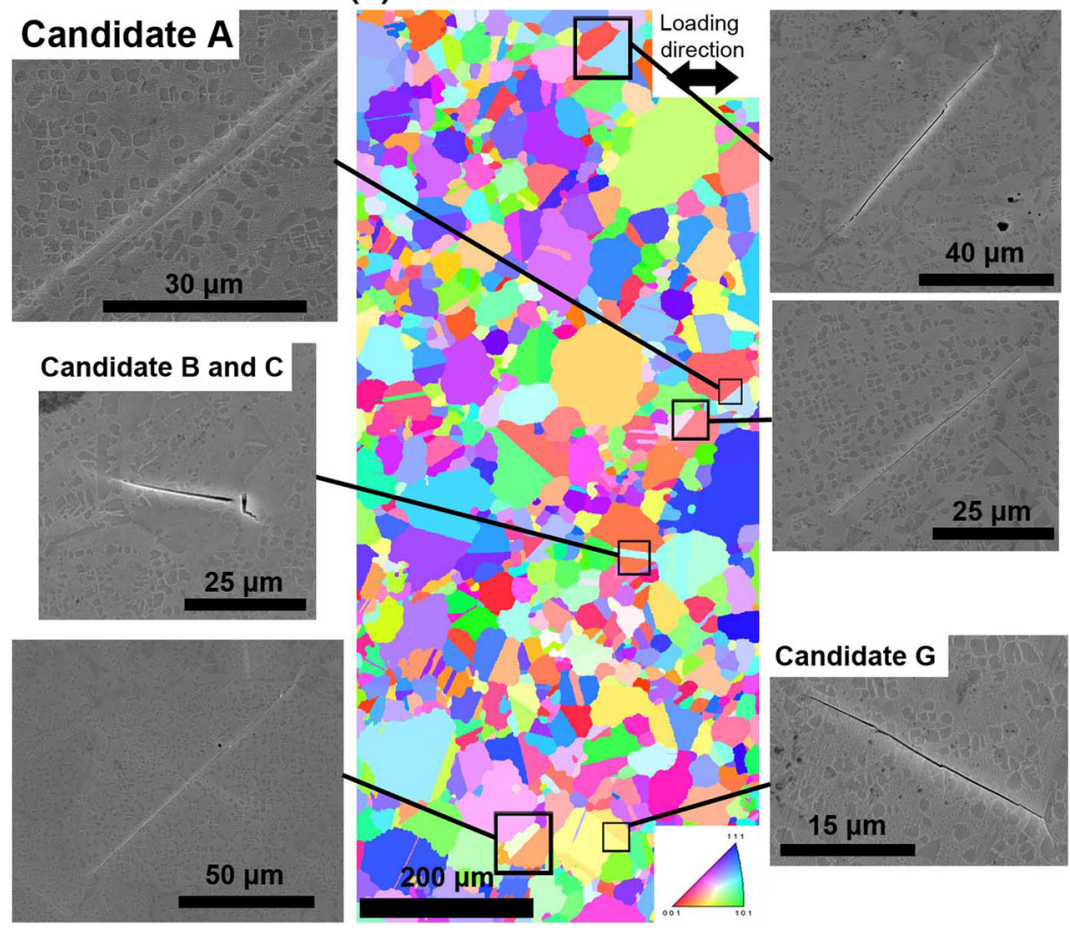

Fig. 11 a The criteria for fatigue crack initiation are applied using a threshold on twin boundary length, elastic modulus difference and maximum Schmid factor on twin and parent grains that have the slip system with the highest Schmid factor parallel to the twin boundary. Initiation candidates extracted from EBSD data are displayed in red. b EBSD map of the region investigated by secondary electron microscopy after fatigue test interrupted at $80 \%$ of the lifetime for IN100. All experimental observed cracks are displayed in (b)
It has been noted experimentally that clusters, defined as parent grains and their associated twins, that contain several twin boundary candidates for initiation display at most only one unique crack. Examples are given in Fig. 6(f) for the René 88DT and for the candidates labelled (C, D) and (E, F, G) in Fig. 11a for the IN100. It is expected that crack initiation along a twin boundary will relax the stresses on the nearby twin boundaries within the cluster, reducing the likelihood for further cracks to form. In order to take this experimental observation into account, a sampling procedure for the analysis of clusters was employed and a unique initiation candidate per cluster was counted in the calculation of the crack density calculations obtained from simulation. The crack density obtained from the cluster analysis is compared to the experimentally measured crack densities in Table 2 for IN100 and René 88DT. It is observed that the predicted crack density from the initiation criteria is an order of magnitude higher com- pared to the experimental crack density, over-predicting the total number of crack initiation sites. Example candidates labelled "candidate A" and "Candidate $\mathrm{H}$ " in Fig. 11 do not experimentally develop cracks. As discussed further in the following section, this is likely due to local stress differences in distribution in selected clusters due to variations in the orientations of grains surrounding the potential initiation sites, i.e., the grain neighborhood.

\subsection{Property surface elements for crack initiation}

A property volume element for fatigue crack initiation was defined by systematically sampling areas from EBSD scans and computing the sampling size at which the variability in the crack initiation density per area converges below a threshold. Square surface elements with edge lengths ranging from 5 to $1500 \mu \mathrm{m}$ were used to calculate the frequency of initiation sites from the 
Table 2 Crack density from experimental data and from computed boundaries that meet the criteria for fatigue crack initiation

\begin{tabular}{lcc}
\hline $\begin{array}{l}\text { Crack density } \\
(\text { number of crack } \\
\left.\text { per } \mathrm{mm}^{2}\right)\end{array}$ & IN100 & René 88DT \\
\hline $\begin{array}{l}\text { Criteria-simulation } \\
\text { (single candidate } \\
\text { by cluster) }\end{array}$ & 25.6 & 132.7 \\
Experimental & & \\
\hline
\end{tabular}

initiation criteria for IN100 and René 88DT. For each square surface element, all clusters which are intercepted by the square element are sampled. A schematic of this procedure is given in Fig. 12. For each square surface element, the cumulative area of the clusters, the number of clusters and the initiation candidates are recorded. At most, one unique initiation candidate per cluster was counted for the total number of initiation candidates. For each square element size, 20 volumes were randomly sampled from the full dataset, which are $\mathrm{mm}^{2}$-scaled with a $1 \mu \mathrm{m}$ scan resolution for the IN100 and $0.4 \mu \mathrm{m}$ for the René 88DT. The initiation candidate density per square millimeter is presented in Fig. 13a with respect to the square element size. Convergence is defined as an $80 \%$ confidence that the population mean was within $5 \%$ of the sample average. Convergence occurs at square element sizes greater than $1212 \times 1212$ and $877 \times 877 \mu \mathrm{m}^{2}$ for IN100 and René 88DT respectively. The vertical line, overlaid on Fig. 13, indicates the $80 \%$ confidence interval to within $5 \%$ of the sample mean. Higher degrees of confidence would require even larger datasets. If a more stringent confidence interval is enforced, convergence does not occur within the entire EBSD dataset size for the René 88DT $\left(\sim 1 \mathrm{~mm}^{2}\right)$, indicating the fatigue crack initiation property element size is larger than the area sampled. The initiation candidate density per cluster is presented in Fig. $13 \mathrm{~b}$ as a function of the number of sampled clusters for both materials. This representation is independent of the grain size. The René 88DT superalloy has significantly higher crack initiation candidate density per cluster in comparison to IN100. From the sampling procedure, it has been observed that the minimum square element size to intercept at least one cluster that contains an initiation candidate is $396 \times 396 \mu \mathrm{m}^{2}(306$ clusters) and $110 \times 110 \mu \mathrm{m}^{2}$ (66 clusters) for IN100 and René 88DT, respectively.

\section{Discussion}

\subsection{Strain localization and crack initiation}

Strain localization and crack initiation during monotonic and cyclic loading has been investigated for powder metallurgy polycrystalline nickel-based superalloys René 88DT and IN100 at room temperature. In both alloys, strain localization and the onset of fatigue damage occurs near coherent twin boundaries during fatigue at room temperature. René 88DT contains a higher density of annealing twins (46\% in twin boundary length fraction) than IN100, which has less than half of the twin boundary density (22\%), influencing the crack initiation site density as shown in Table 2.

Crystallographic orientation, grain shape and size, and neighboring microstructure are the relevant parameters for the crack initiation and propagation processes (Miao et al. 2009; Heinz and Neumann 1990; Shyam et al. 2004; Li et al. 2004; Davidson et al. 2007; Polak 2003). At the microscopic scale, crack initiation is dominated by localization of plastic strain in persistent slip bands (PSBs) (Mughrabi 2009; Laird and Duquette 1972; Bayerlein and Mughrabi 1992). In the case of a fcc material containing coherent twins, the twin boundary is parallel to a $\{111\}$ slip plane. Therefore a parallel slip configuration (Stinville et al. 2016) where an activated $\{111\}\langle 110\rangle$ slip plane is parallel to the twin plane may be present. An activated slip system parallel to a twin boundary (possible with a coherent twin boundary and parallel slip configuration) allows for dislocations to travel relatively long distances unhindered, creating high local strains and correspondingly high incompatibility stresses at the boundary (Heinz and Neumann 1990). Stein et al. (2014), Cerrone et al. (2013) and Yeratapally et al. (2016), have shown by crystal plasticity calculations that the resolved shear stresses at twin boundaries with a parallel slip configuration results in a low and high stress state on either side of the twin boundary. Miao et al. (2012) and Stinville et al. (2015c) have experimentally detected high shear strains with enhanced local plastic straining in the parallel slip configuration in the vicinity of twin boundaries in René 88DT during monotonic and cyclic loading at room temperature.

Strain localization and crack initiation preferentially originate in grains with relatively high maximum Schmid factor (calculated assuming uniaxial loading) on the $\{111\}\langle 110\rangle$ slip systems as shown in Figs. 1, 2 
Fig. 12 Subsampling routine used to investigate the microstructure element size for fatigue crack initiation. a Square surface sampling elements with defined edge lengths randomly positioned within a large EBSD map. b Extraction of clusters which are connected to the square surface sampling element. c Area of all clusters that belong to the square surface sampling element, number of clusters within the surface sampling element, number of clusters within the surface sampling element that have one or several initiation candidates are extracted

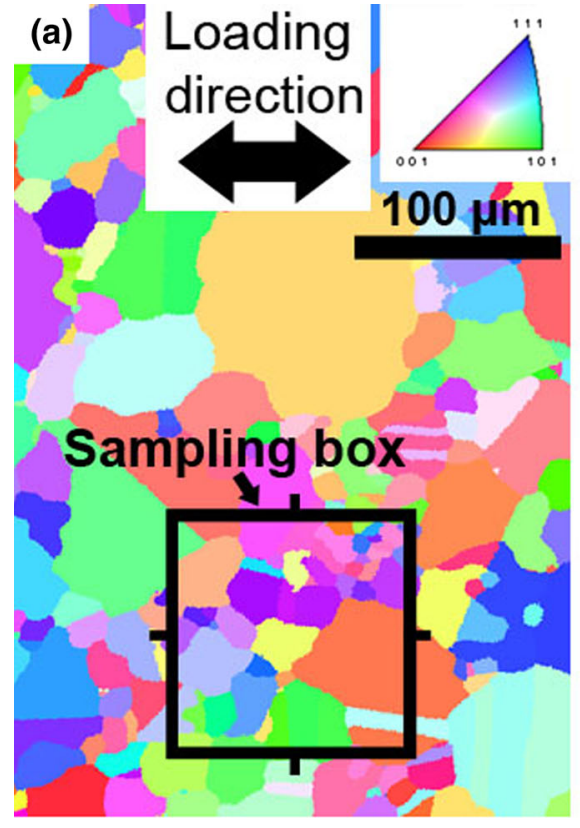

(b) Clusters in samping box

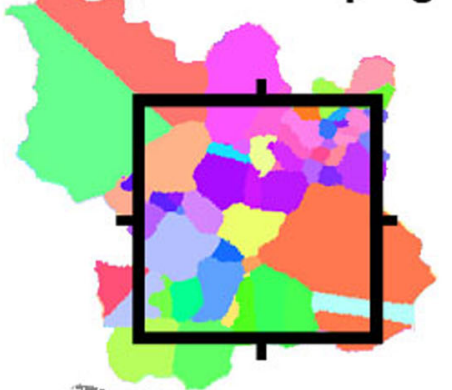

(c) Initiąión candidate

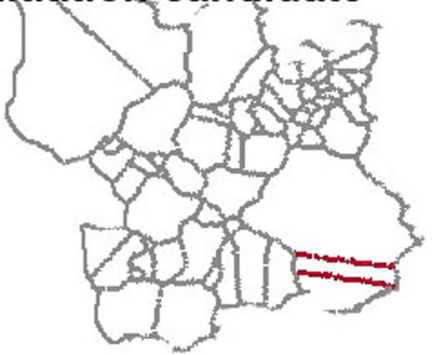

(a)

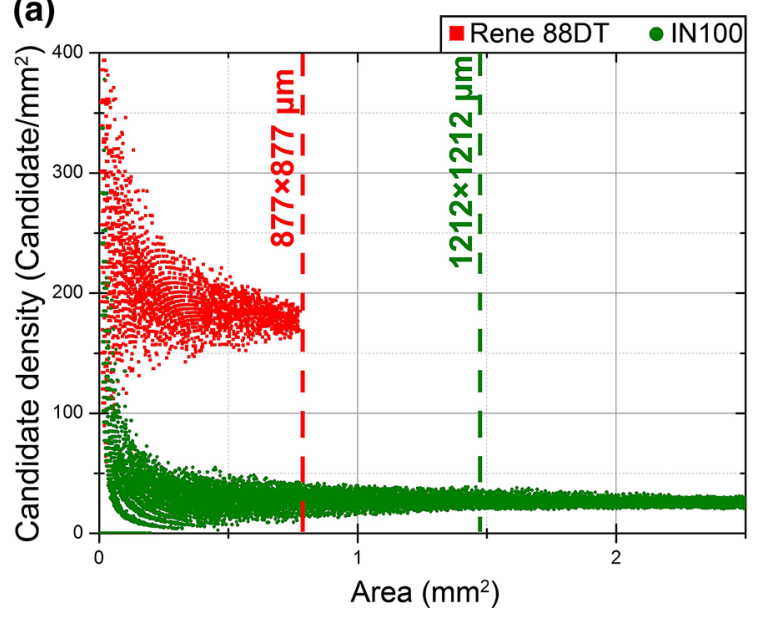

Fig. 13 a The initiation candidate area density plotted against sampling area with 20 boxes selected at random locations for sizes ranging from 5 to $1000 \mu \mathrm{m}$ for IN100 and René 88DT. The vertical lines indicate $80 \%$ confidence convergence to within

and 5. Favorably oriented grains have a high resolved shear stress on the slip system parallel to the twin boundary, inducing early plasticity, which may accumulate during cycling. Large crystallographic facets are systematically observed for the initiation site indicating that a long twin boundary is associated with crack initiation. Previous studies in nickel (Morrison and Moosbrugger 1997), copper (Thompson et al. (b)

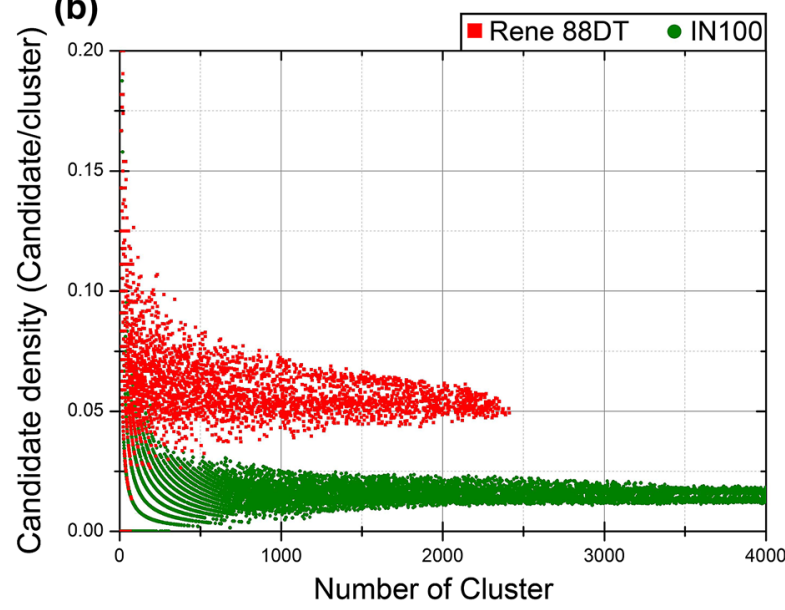

$5 \%$ of the sample mean. b The initiation candidate cluster density plotted against number of clusters with 20 boxes selected at random location for sizes raging from 5 to $1000 \mu \mathrm{m}$ for IN100 and René 88DT

1956; Boettner et al. 1964), and steel (Mineur et al. 2000) clearly indicate that grain size influences cyclic plasticity and fatigue crack initiation mechanisms. The fatigue crack initiation model proposed by Tanaka and Mura (1981) and later refined by Lin et al. (1986) and Mura and Nakasone (1990) predicts that the number of cycles for crack initiation is proportional to the inverse of the length of the slip plane activated in a grain. The 
irreversibility of dislocation motion, which is strongly enhanced by the presence of the $\gamma^{\prime}$ precipitates, yields an increase in the dislocation density in pileups during cycling (Mughrabi 2006). It is therefore reasonable to conclude that the length of the twin boundary affects crack initiation, since they are correlated in the parallel slip configuration. Another major parameter influencing crack initiation is the elastic modulus difference between the twin and parent grain. Heinz and Neumann (1990) first suggested that elastic anisotropy causes a local stress concentration that strongly enhances glide at twin boundaries. Figures 5 and 7 a show that a large difference in elastic modulus favors strain localization and crack initiation near the twin boundary. The elastic modulus difference between twin grain pairs in fcc materials can be significant, producing a local stress concentration nearby the twin boundary (Stein et al. 2014; Cerrone et al. 2013; Yeratapally et al. 2016). In superalloys with high Zener elastic anisotropy ratios (greater than 2), the localization effect is further enhanced localizing stresses and nucleating slip bands. For grains with a very high Schmid factor on a $\{111\}\langle 110\rangle$ slip system, the elastic modulus difference between the twin and parent grain in the parallel slip configuration is theoretically low. However, for twin and parent grains with lower Schmid factors, the difference can be significant.

The elastic modulus difference across the grain boundary, the Schmid factor, and the twin boundary length, in addition to the parallel slip configuration are parameters that can be applied in a straightforward manner to identify crack initiation sites. Their interplay is presented in Fig. 7 for IN100 and René 88DT, and is shown in more detail elsewhere for René 88DT (Stinville et al. 2016). These parameters bound the domain for crystallographic crack initiation at room temperature as displayed in Fig. 7. Considering the grains to be uniaxially loaded for both the calculation of the resolved shear stress (Schmid factor) and for the elastic modulus difference is a significant assumption, since the local stress at the boundary can be affected by the surrounding microstructural configuration. However, this assumption is sufficient for predicting strain localization but significantly over-predicting crack initiation sites by an order of magnitude. This indicates that early strain localization is primarily governed by the local configuration (twin boundary) while crack initiation is additionally influenced by the surrounding microstructural neighborhood (surrounding grain structure). The stress concentrations associated with the surrounding neighborhood require a more detailed mechanics analysis; crystal plasticity analyses of 3D datasets will provide a more detailed assessment (Ghosh et al. 2015). Importantly the procedure for identifying grain clusters where initiation is likely provides a means for selecting an analysis region and reducing the number of elements required for a detailed finite element calculation.

The Schmid factor and the elastic modulus difference across twin boundaries are parameters that assess the degree of deformation localization that occurs by slip during monotonic loading. However, these parameters are insufficient for estimation of the increase in localization from cyclic loading. The increased localization during fatigue that contributes to crack initiation is observed to be sensitive to other parameters (Yeratapally et al. 2016; Pineau and Antolovich 2009; Mughrabi 2006). The irreversibility of dislocation motion yields a systematic increase in the dislocation density in pileups during cycling (Mughrabi 2006). Once pileups develop, crack initiation and crack transmission from the initial grain to the neighboring grain will be influenced by the orientation of the surrounding grains and likely the character of the grain boundary, which may prevent or enhance the transmission process. Grain boundaries that favor dislocation transmission are more likely to suppress the degree of localization along slip bands and therefore inhibit crack initiation. In these conditions, the initiation criteria used in this manuscript can also identify some of the localization sites that may not favor crack initiation during fatigue. The crack initiation criteria does correctly predict the locations where plastic localization occurs during deformation as shown in Fig. 14 for the IN100. Furthermore, at the location of each initiation candidate site high strain localization occurred, as shown by black arrows in Fig. 14a.

Computational algorithms for analysis of large datasets permit statistical analysis of datasets in order to establish the size of a microstructural volume element for fatigue crack initiation and highlight the importance of each parameters in the initiation criteria. Investigation of large EBSD scans indicate that only $13.2 \%$ and $14.5 \%$ of twin boundaries in IN100 and René 88DT are in the parallel slip configuration, where twin boundaries have the slip system with the maximum Schmid factor parallel to the twin boundary. The elastic modulus difference-maximum Schmid factor criteria removes 
Fig. 14 a The criteria for fatigue crack initiation is applied using a threshold on twin boundary length, elastic modulus difference and maximum Schmid factor on twin and parent grains that have a slip system with the highest Schmid factor parallel to the twin boundary. Initiation candidates extracted from EBSD data are displayed in red. b Strain field $\epsilon_{x x}$ from high resolution DIC after $1 \%$ c macroscopic strain in tension for IN100 (a) Initiation candidate

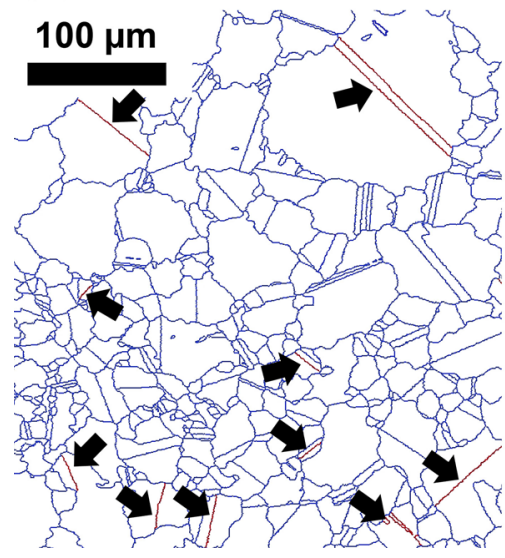

(b) $1 \%$ macroscopic strain

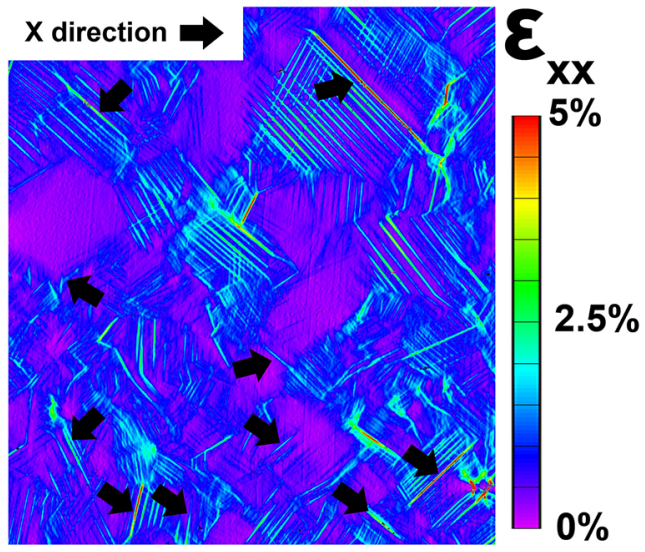

$34.4 \%$ and $32.5 \%$ of twin boundaries in IN100 and René 88DT that are in a parallel slip configuration from potential initiation candidates. The boundary lengthmaximum Schmid factor criteria removes $80.1 \%$ and $73.6 \%$ of all twin boundaries in IN100 and René 88DT that are in a parallel slip configuration from potential initiation candidates. It is observed that the boundary length criteria is a stronger criteria in comparison to the elastic modulus difference criteria. The superposition of all of these criteria result in $1.0 \%$ of the IN100 boundaries by length and $2.9 \%$ of the boundary lengths in René 88D provide favorable conditions for the localization of strain and subsequent crack initiation.

\subsection{Converged volume element size}

Using previously reported data for René 88DT (Stinville et al. 2016), the volume element size for strain localization, defined as a $80 \%$ confidence that the population mean is within 5\% of the sample average, can be calculated as $220 \times 220 \mu \mathrm{m}^{2}$. The obtained converged volume element size for crack initiation is significantly larger than the volume element size for strain localization. For this level of confidence and with the consideration of grain clusters, the initiation candidate density convergence occurs for areas greater than $1212 \times 1212 \mu \mathrm{m}^{2}$ (28 times the average grain size) and $877 \times 877 \mu \mathrm{m}^{2}$ (34 times the average grain size) for IN100 and René 88DT respectively. The maximum sampling element area size needed to intercept at least one grain cluster that contains an initia- tion candidate is $396 \times 396 \mu \mathrm{m}^{2}$ and $110 \times 110 \mu \mathrm{m}^{2}$ for IN100 and René 88DT respectively. This corresponds to 306 and 66 surface clusters for the IN100 and René 88DT respectively. Therefore, significantly large areas are necessary to predict the variability in fatigue.

The present analyses provide guidance for changes in microstructure that could improve fatigue properties. Since IN100 has an average grain size that is about two times higher than René 88DT, the crack density property element for crack initiation is significantly larger for the IN100 superalloy. Regardless of the difference in grain size, the candidate density per grain cluster indicates that the IN100 has a larger property element size compare to the René 88DT. For instance, 306 neighbouring grain clusters are necessary to capture at least one initiation candidate in IN100, while 66 clusters are sufficient for the René 88DT. This is explained by a significantly lower fraction of twin boundaries in IN100. Moreover the number of twin boundary variants in René 88DT is higher than the IN100 superalloy. For example, it is not uncommon to observe René 88DT clusters that have 2 or 3 different variants of twin boundaries per cluster. These differences are driven by variations in processing and subsequent heat treatment as well as alloy composition. From the perspective of fatigue, in spite of the fact that the twin domains promote strain localization, a higher density of twins may degrade fatigue properties, but this can be offset by reducing the mean and the variability of the grain size. Further, high twins densities are likely to reduce property variability. 


\section{Conclusions}

Digital image correlation and algorithms for analysis of the grain and twin structure of two nickel base superalloys have been employed to assess the size of microstructural volume elements relevant to strain localization and fatigue crack initiation.

1. The crack initiation sites are observed to occur near twin boundaries with slip systems activated parallel to the twin boundary. The elastic-plastic loading parameters (elastic modulus and Schmid factor) along with the size of twin boundaries that satisfy the parallel slip condition bound a domain where crack initiation occurs.

2. This crack initiation criteria was applied to experimentally gathered microstructural (EBSD) datasets and compared to fatigue crack initiation locations measured after cyclic loading of superalloy samples. The relative strength of each of the parameters that define the initiation criteria can also be examined by computing the initiation candidate boundaries on large experimentally gathered datasets. The density of fatigue crack initiation sites was compared to those predicted using the crack initiation criteria, where a 10x site over-prediction was observed, however all experimentally observed crack initiation sites were successfully identified by our crack initiation criteria.

3. A convergence based approach was used to define the statistical surface volume element size necessary to capture a crack initiation event, which are $396 \times 396 \mu \mathrm{m}^{2}$ and $110 \times 110 \mu \mathrm{m}^{2}$ for IN100 and René 88DT, respectively. In order for the crack initiation candidate density to converge, defined as a $80 \%$ confidence that the population mean is within $5 \%$ of the sample average, areas greater than 1212 $\times 1212$ and $877 \times 877 \mu \mathrm{m}^{2}$ for IN100 and René 88DT were required.

4. The statistical surface volume element for crack initiation is significantly larger for IN100 in comparison to René 88DT. This is explained by a significantly lower fraction of twin boundaries in IN100 as well as a larger grain size.

Acknowledgements The authors gratefully acknowledge the support of GE Global Research and appreciate useful discussions with J. Laflen, A. Loghin, J. Marte, M. Groeber, M. Jackson and M. Uchic. This work has been supported through a Grant No. FA9550-12-1-0445 to the Center of Excellence on Integrated Materials Modeling (CEIMM) at Johns Hopkins Univer- sity, awarded by the AFOSR/ Aerospace Materials for Extreme Environments Program (Program Manager Dr. Ali Sayir) and AFRL/RX (Monitors Drs. C. Woodward and C. Przybyla).

\section{References}

Bayerlein M, Mughrabi H (1992) Fatigue crack initiation and early crack growth in copper polycrystals-effects of temperature and environment. Short Fatigue Cracks, ESIS 13, Mech. Eng. Publications, pp 55-82

Boettner RC, McEvily AJ Jr, Liu YC (1964) On the formation of fatigue cracks at twin boundaries. Philos Mag 10(103):95106. doi:10.1080/14786436408224210

Cerrone A, Spear A, Tucker J, Stein CA, Rollett AD, Ingraffea AR (2013) Modeling crack nucleation at coherent twin boundaries in nickel—modeling crack nucleation at coherent twin boundaries in nickel-based superalloys. Mater Sci Technol (MS\&T) 1649

Cowles BA (1989) High cycle fatigue in aircraft gas turbine-an industry perspective. Int J Fract 80(2-3):147-163

Davidson DL, Tryon RG, Oja M, Matthews R, Ravi Chandran KS (2007) Fatigue crack initiation in waspaloy at 20

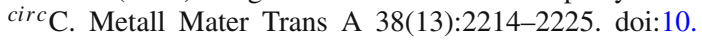
1007/s11661-007-9178-6. ISSN 1543-1940

Di Gioacchino F, Quinta da Fonseca J (2013) Plastic strain mapping with sub-micron resolution using digital image correlation. Exp Mech 53(5):743-754

Echlin MLP, Pollock TM (2013) A statistical sampling approach for measurement of fracture toughness parameters in a 4330 steel by 3-D femtosecond laser-based tomography. Acta Mater 61(15):5791-5799. doi:10.1016/j.actamat.2013.06. 023

Echlin MLP, Husseini NS, Nees JA, Pollock TM (2011) A new femtosecond laser-based tomography technique for multiphase materials. Adv Mater 23(20):2339-2342. doi:10. 1002/adma.201003600. ISSN 1521-4095

Echlin MLP, Lenthe WC, Pollock TM (2014) Three-dimensional sampling of material structure for property modeling and design. Integr Mater Manuf Innov 3(1):21. doi:10.1186/ s40192-014-0021-9. ISSN 2193-9764

Echlin MLP, Straw M, Randolph S, Filevich J, Pollock TM (2015) The tribeam system: femtosecond laser ablation in situ SEM. Mater Charact 100:1-12. doi:10.1016/j.matchar. 2014.10.023. ISSN 1044-5803

Ghosh S, Weber G, Keshavarz S (2015) Multiscale modeling of polycrystalline nickel-based superalloys accounting for subgrain microstructures. Mech Res Commun. doi:10. 1016/j.mechrescom.2015.12.001. ISSN 0093-6413

Gitman IM, Askes H, Sluys LJ (2007) Representative volume: existence and size determination. Eng Fract Mech 74(16):2518-2534. doi:10.1016/j.engfracmech.2006.12. 021. ISSN 0013-7944

Groeber M, Haley BK, Uchic MD, Dimiduk DM, Ghosh S (2006) 3D reconstruction and characterization of polycrystalline microstructures using a FIB-SEM system. Mater Charact 57(4-5):259-273. doi:10.1016/j.matchar.2006.01. 019. ISSN 1044-5803

Groeber M, Ghosh S, Uchic MD, Dimiduk DM (2008) A framework for automated analysis and simulation of $3 \mathrm{D}$ poly- 
crystalline microstructures. Part 2: synthetic structure generation. Acta Mater 56(6):1274-1287

Heinz A, Neumann P (1990) Crack initiation during high cycle fatigue of an austenitic steel. Acta Metall Mater 38(10):1933-1940. doi:10.1016/0956-7151(90)90305-Z. ISSN 0956-7151

Hill R (1963) Elastic properties of reinforced solids: some theoretical principles. J Mech Phys Solids 11(5):357-372. doi:10.1016/0022-5096(63)90036-X. ISSN 0022-5096

Jiang R, Pierron F, Octaviani S, Reed PAS (2017) Characterisation of strain localisation processes during fatigue crack initiation and early crack propagation by SEM-DIC in an advanced disc alloy. Mater Sci Eng A 699:128-144. doi:10. 1016/j.msea.2017.05.091. ISSN 0921-5093

Jiang J, Zhang T, Dunne FPE, Britton TB (2016) Deformation compatibility in a single crystalline Ni superalloy. In: Proc. R. Soc. A, vol 472

Kammers AD, Daly S (2013) Self-assembled nanoparticle surface patterning for improved digital image correlation in a scanning electron microscope. Exp Mech 53(8):1333-1341. doi:10.1007/s11340-013-9734-5. ISSN 0014-4851

Krueger DD, Kissinger RD, Menzies RG (1992) Development and introduction of a damage tolerant high temperature nickel-base disk alloy. In: Antolovich SD (ed) Superalloys. TMS-AIME, Warrendale, pp 277-286

Kumar A, Torbet CJ, Pollock TM, Jones JW (2010) In situ characterization of fatigue damage evolution in a cast al alloy via nonlinear ultrasonic measurements. Acta Mater 58(6):2143-2154

Laird C, Duquette DJ (1972) Mechanisms of fatigue crack nucleation. Corrosion Fatigue, National Association of Corrosion Engineers, pp 88-117

Lenthe WC, Stinville JC, Echlin MP, Pollock TM (2016) Statistical assessment of fatigue-initiating microstructural features in a polycristalline disk alloy. Superalloys 2016:569-577

Li K, Ashbaugh NE, Rosenberger AH (2004) Crystallographic initiation of nickel-base superalloy IN100 at RT and $538^{\circ} \mathrm{C}$ under low cycle fatigue conditions. Superalloys 2004:251

Lin MR, Fine ME, Mura T (1986) Fatigue crack initiation on slip bands: theory and experiment. Acta Metall 34(4):619-628. doi:10.1016/0001-6160(86)90177-X. ISSN 0001-6160

McDowell DL, Ghosh S, Kalidindi SR (2011) Representation and computational structure-property relations of random media. JOM 63(3):45-51. doi:10.1007/ s11837-011-0045-y. ISSN 1543-1851

Miao J, Pollock TM, Jones JW (2008) Fatigue crack initiation in nickel-based superalloy rené 88 DT at 593 C. In: Caron P, Gabb TP, Fahrmann MG, Huron ES, Woodard SA, Reed RC, Green KA (eds) Superalloys. TMS, Warrendale, pp 589597

Miao J, Pollock TM, Wayne Jones J (2009) Crystallographic fatigue crack initiation in nickel-based superalloy René 88DT at elevated temperature. Acta Mater 57(20):59645974. doi:10.1016/j.actamat.2009.08.022

Miao J, Pollock TM, Wayne Jones J (2012) Microstructural extremes and the transition from fatigue crack initiation to small crack growth in a polycrystalline nickel-base superalloy. Acta Mater 60(6-7):2840-2854. doi:10.1016/ j.actamat.2012.01.049. ISSN 1359-6454
Milligan WW, Orth E, Schirra J, Savage M (2004) Effects of microstructure on the high temperature constitutive behavior of IN100. Superalloys 2004:331-339

Mineur M, Villechaise P, Mendez J (2000) Influence of the crystalline texture on the fatigue behavior of a $316 \mathrm{~L}$ austenitic stainless steel. Mater Sci Eng A 286(2):257-268. doi:10. 1016/S0921-5093(00)00804-2. ISSN 0921-5093

Morrison DJ, Moosbrugger JC (1997) Effects of grain size on cyclic plasticity and fatigue crack initiation in nickel. Int J Fatigue 19(93):51-59. doi:10.1016/ S0142-1123(97)00034-0. ISSN 0142-1123

Mughrabi H (2006) Specific features and mechanisms of fatigue in the ultrahigh-cycle regime. Int J Fatigue 28:501-508

Mughrabi H (2009) Cyclic slip irreversibilities and the evolution of fatigue damage. Metall Mater Trans A 40(6):1257-1279. doi:10.1007/s11661-009-9839-8

Mura T, Nakasone Y (1990) A theory of fatigue crack initiation in solids. J Appl Mech 57(1):1-6

Niezgoda SR, Turner DM, Fullwood DT, Kalidindi SR (2010) Optimized structure based representative volume element sets reflecting the ensemble-averaged 2-point statistics. Acta Mater 58(13):4432-4445. doi:10.1016/j.actamat. 2010.04.041. ISSN 1359-6454

Ostoja-Starzewski M (2006) Material spatial randomness: from statistical to representative volume element. Probab Eng Mech 21(2):112-132. doi:10.1016/j.probengmech.2005. 07.007. ISSN 0266-8920

Pineau A, Antolovich SD (2009) High temperature fatigue of nickel-base superalloys-a review with special emphasis on deformation modes and oxidation. Eng Fail Anal 16(8):2668-2697. doi:10.1016/j.engfailanal.2009.01. 010. ISSN 1350-6307. Special issue honouring Professor Manuel Elices on the occasion of his 70th birthday

Polak J (2003) Cyclic deformation, crack initiation, and low cycle fatigue. Compr Struct Inegrity 4:1-39

Pollock TM, Tin S (2006) Nickel-based superalloys for advanced turbine engines: chemistry, microstructure and properties. J Propuls Power 22(2):361-374

Qidwai SM, Turner DM, Niezgoda SR, Lewis AC, Geltmacher AB, Rowenhorst DJ, Kalidindi SR (2012) Estimating the response of polycrystalline materials using sets of weighted statistical volume elements. Acta Mater 60:5284-5299. doi:10.1016/j.actamat.2012.06.026. ISSN 1359-6454

Reed RC (2006) The superalloys: fundamentals and applications. Cambridge University Press, Cambridge. ISBN 9781139458634

Rosca D, Morawiec A, De Graef M (2014) A new method of constructing a grid in the space of $3 \mathrm{D}$ rotations and its applications to texture analysis. Modell Simul Mater Sci Eng 22(7):075013

Shan Z, Gokhale AM (2002) Representative volume element for non-uniform micro-structure. Comput Mater Sci 24(3):361-379. doi:10.1016/S0927-0256(01)00257-9. ISSN 0927-0256

Shyam A, Torbet CJ, Jha SK, Larsen JM, Caton MJ, Szczepanski CJ, Pollock TM, Jones JW (2004) Development of ultrasonic fatigue for rapid, high temperature fatigue studies in turbine engine materials. Superalloys 2004:259-268 
Stein C, Lee S, Rollett A (2012) An analysis of fatigue crack initiation using 2D orientation mapping and full-field simulation of elastic stress response, superalloys. Superalloy 2012

Stein CA, Cerrone A, Ozturk T, Lee S, Kenesei P, Tucker H, Pokharel R, Lind J, Hefferan C, Suter RM, Ingraffea AR, Rollett AD (2014) Fatigue crack initiation, slip localization and twin boundaries in a nickel-based superalloy. Curr Opin Solid State Mater Sci 18(4):244-252. doi:10.1016/ j.cossms.2014.06.001. ISSN 1359-0286, Slip Localization and Transfer in Deformation and Fatigue of Polycrystals

Stinville JC, Echlin MP, Texier D, Bridier F, Bocher P, Pollock TM (2015a) Sub-grain scale digital image correlation by electron microscopy for polycrystalline materials during elastic and plastic deformation. Exp Mech 1-20: doi:10. 1007/s11340-015-0083-4. ISSN 1741-2765

Stinville JC, Lenthe WC, Miao J, Pollock TM (2015b) A combined grain scale elastic-plastic criterion for identification of fatigue crack initiation sites in a twin containing polycrystalline nickel-base superalloy. Acta Mater 103:461-473. doi:10.1016/j.actamat.2015.09.050. ISSN 13596454

Stinville JC, Vanderesse N, Bridier F, Bocher P, Pollock TM (2015c) High resolution mapping of strain localization near twin boundaries in a nickel-based superalloy. Acta Mater 98:29-42. doi:10.1016/j.actamat.2015.07.016. ISSN 13596454

Stinville JC, Lenthe WC, Miao J, Pollock TM (2016) A combined grain scale elastic-plastic criterion for identification of fatigue crack initiation sites in a twin containing polycrystalline nickel-base superalloy. Acta Mater 103:461-473. doi:10.1016/j.actamat.2015.09.050. ISSN 1359-6454
Swaminathan S, Ghosh S, Pagano NJ (2006) Statistically equivalent representative volume elements for unidirectional composite microstructures: part I-without damage. J Compos Mater 40(7):583-604

Tanaka K, Mura T (1981) A dislocation model for fatigue crack initiation. J Appl Mech 48(1):97-103

Texier D, Gómez AC, Pierret S, Franchet J-M, Pollock TM, Villechaise P, Cormier J (2016) Microstructural features controlling the variability in low-cycle fatigue properties of alloy inconel 718DA at intermediate temperature. Metall Mater Trans A 47(3):1096-1109. doi:10.1007/ s11661-015-3291-8. ISSN 1543-1940

Thompson N, Wadsworth N, Louat N (1956) Xi. The origin of fatigue fracture in copper. Philos Mag 1(2):113-126. doi:10. 1080/14786435608238086

Vic-2D (2009) software. Correlated Solutions Inc., Columbia, $\mathrm{SC}$

Wong SL, Dawson PR (2010) Influence of directional strengthto-stiffness on the elastic-plastic transition of fcc polycrystals under uniaxial tensile loading. Acta Mater 58(5):1658 1678. doi:10.1016/j.actamat.2009.11.009. ISSN 1359-6454

Yeratapally SR, Glavicic MG, Hardy M, Sangid MD (2016) Microstructure based fatigue life prediction framework for polycrystalline nickel-base superalloys with emphasis on the role played by twin boundaries in crack initiation. Acta Mater 107:152-167. doi:10.1016/j.actamat.2016.01. 038. ISSN 1359-6454 